\title{
HEPATOLOGY
}

\section{INTENTION-TO-TREAT SURVIVAL BENEFIT OF LIVER TRANSPLANTATION IN PATIENTS WITH HEPATOCELLULAR CANCER}

\begin{tabular}{|c|c|}
\hline Journal: & Hepatology \\
\hline Manuscript ID & HEP-16-2270.R1 \\
\hline Wiley - Manuscript type: & Original \\
\hline Date Submitted by the Author: & 10-May-2017 \\
\hline Complete List of Authors: & $\begin{array}{l}\text { Lai, Quirino } \\
\text { Vitale, Alessandro; Padua University Hospital, Chirurgia Epatobiliare e } \\
\text { Trapianto Epatico } \\
\text { Iesari, Samuele } \\
\text { Finkenstedt, Armin; Medical University of Innsbruck, Department of } \\
\text { Medicine, Division of Gastroenterology and Hepatology } \\
\text { Mennini, Gainluca } \\
\text { Spoletini, Gabriele } \\
\text { Hoppe-Lotichius, Maria; Johannes Gutenberg University, Department of } \\
\text { Transplantation and Hepatobiliopancreatic Surgery } \\
\text { Vennarecci, Giovanni; San Camillo Hospital, transplantation } \\
\text { Manzia, Tommaso; Tor Vergata University, U.O.C.Trapianti d'Organo } \\
\text { Nicolini, Daniele; Hepatobiliary and Transplant Surgery, Department of } \\
\text { Gastroenterology and Transplantation } \\
\text { Avolio, Alfonso } \\
\text { Frigo, Anna Chiara; University of Padova, Dept. of Enviromental Medicine } \\
\text { and Public Health } \\
\text { Cillo, Umberto; University of Padova, Surgery and Oncology } \\
\text { Graziadei, Ivo; Academic Teaching Hospital Hall, Department of Internal } \\
\text { Medicine } \\
\text { Rossi, Massimo } \\
\text { Tsochatzis, Emmanuel; Royal Free Hospital, The Royal Free Sheila Sherlock } \\
\text { Liver Centre and UCL Institute of Liver and Digestive Health ; } \\
\text { Otto, Gerd; University Medical Center, } \\
\text { Ettorre, Giuseppe; San Camillo Hospital, General Surgery and } \\
\text { Transplantation Unit } \\
\text { Tisone, G; S. Eugenio Hospital Roma italy, Surgical clinic } \\
\text { Vivarelli, Marco; Hepatobiliary and Transplant Surgery, Department of } \\
\text { Gastroenterology and Transplantation } \\
\text { Agnes, Salvatore; "A.Gemelli" Catholic University of Rome, Dept of Surgery } \\
\text { - Transplantation Service } \\
\text { Lerut, Jan; Cliniques Universitaires Saint-Luc, ; }\end{array}$ \\
\hline Keywords: & Radiological response, MELD, alpha-fetoprotein, Milan Criteria, mRECIST \\
\hline
\end{tabular}




\section{Page 1 of 42}

1

2

3

4

5

6

7

8

9

10

11

12

13

14

15

16

17

18

19

20

21

22

23

24

25

26

27

28
29

30

31

32

33

34

35

36

37

38

39

40

41

42

43

44

45

46

47

48

49

50

51

52

53

54

55

56

57

58

59

60

SCHOLARONE ${ }^{m}$

Manuscripts

Hepatology 


\section{INTENTION-TO-TREAT SURVIVAL BENEFIT OF LIVER TRANSPLANTATION IN PATIENTS WITH HEPATOCELLULAR CANCER}

Lai Q*, M.D. ${ }^{1}$ Vitale A*, M.D. ${ }^{2}$ Iesari S, M.D. ${ }^{1}$ Finkenstedt A, M.D. ${ }^{3}$ Mennini G, M.D. ${ }^{4}$ Spoletini G, M.D. ${ }^{5}$ Hoppe-Lotichius M, M.D. ${ }^{6}$ Vennarecci G, M.D. ${ }^{7}$ Manzia TM, M.D. ${ }^{8}$ Nicolini D, M.D. ${ }^{9}$ Avolio AW, M.D. ${ }^{10}$ Frigo AC, ${ }^{11}$ Cillo U, M.D. ${ }^{2}$ Graziadei I, M.D. ${ }^{12}$ Rossi M, M.D. ${ }^{4}$ Tsochatzis E, M.D. ${ }^{5}$ Otto G, M.D. ${ }^{6}$ Ettorre GM, M.D. ${ }^{7}$ Tisone G, M.D. ${ }^{8}$ Vivarelli M, M.D. ${ }^{9}$ Agnes S, M.D. ${ }^{10}$ Lerut J M.D. ${ }^{1}$, on behalf of the European Hepatocellular Cancer Liver Transplant Study Group

* These Authors equally contributed to this paper

1. Starzl Unit of Abdominal Transplantation, St. Luc University Hospital, Catholic University of Louvain, Brussels, Belgium; 2. Department of Surgery, Oncology and Gastroenterology, University of Padua, Padua, Italy; 3. Gastroenterology and Hepatology, Department of Internal Medicine II, Innsbruck Medical University, Innsbruck, Austria; 4. Department of General Surgery and Organ Transplantation, Umberto I Hospital, Sapienza University, Rome, Italy; 5. UCL Institute for Liver and Digestive Health and Royal Free Sheila Sherlock Liver Centre, Royal Free Hospital and UCL, London, UK; 6. Department of Transplantation and Hepatobiliary Surgery, University of Mainz, Mainz, Germany; 7. Division of General Surgery and Liver Transplantation, San Camillo Hospital, Rome, Italy; 8. Department of Transplant Surgery, Polyclinic Tor Vergata Foundation, Tor Vergata University, Rome, Italy; 9. Unit of Hepatobiliary Surgery and Transplantation, Azienda Ospedaliero-Universitaria "'Ospedali Riuniti,"' Torrette Ancona, Italy; 10. Liver Unit, Department of Surgery, Agostino Gemelli Hospital, Catholic University, Rome, Italy; 11. Biostatistics Unit, University of Padua, Padua, Italy; 12. Academic Teaching Hospital, Hall, Tirol, Austria.

Quirino Lai: 1ai.quirino@libero.it

Alessandro Vitale: alessandro.vitale@unipd.it

Samuele Iesari: samuele.iesari@gmail.com

Armin Finkenstedt: armin.finkenstedt@,tirol-kliniken.at

Gianluca Mennini: gianluca.mennini@uniroma1.it

Gabriele Spoletini: gabriele.spoletini@gmail.com

Maria Hoppe-Lotichius: maria.hoppe-lotichius@unimedizin-mainz.de

Giovanni Vennarecci: gvennarecci@scamilloforlanini.rm.it

Tommaso M Manzia: tomanzia@libero.it

Daniele Nicolini: nicolini daniele@yahoo.it

Alfonso W Avolio: alfonso.avolio@policlinicogemelli.it

Anna Chiara Frigo: annachiara.frigo@unipd.it

Umberto Cillo: cillo@unipd.it

Ivo Graziadei: ivo.graziadei@tirol-kliniken.at

Massimo Rossi: massimo.rossi@uniroma1.it

Emmanouil Tsochatzis: e.tsochatzis@ucl.ac.uk

Gerd Otto: gerd.otto@unimedizin-mainz.de

Giuseppe M Ettorre: gmettorre@scamilloforlanini.rm.it

Giuseppe Tisone: tisone@med.uniroma2.it

Marco Vivarelli: vivarelli63@1ibero.it

Salvatore Agnes: salvatoreagnes@,rm.unicatt.it

Jan Lerut: jan.lerut@uclouvain.be

\section{Keywords}

Radiological response; MELD; alpha-fetoprotein; Milan Criteria, mRECIST. 


\section{Address reprint requests to:}

Quirino Lai, M.D., Ph.D. and Jan Lerut, M.D., Ph.D., F.A.C.S., F.E.B.T.S.

Starzl Abdominal Transplant Unit, University Hospitals Saint Luc,

Université catholique Louvain (UCL),

Avenue Hippocrates 10, 1200 Brussels, Belgium;

Phone: +32 27641412; fax: +32 27649039.

E-mail: lai.quirino@libero.it

jan.lerut@uclouvain.be

Word count: 3801

Tables: 3

\author{
Abstract: 246 \\ Figures: 2
}

Pages: 21

References: 33

\author{
Abbreviations used in the text: \\ AIC, Akaike Information Criterion \\ AFP, alpha-fetoprotein \\ CR, complete response \\ DO, drop-out \\ EurHeCaLT, European Hepatocellular Cancer And Liver Transplantation \\ FU, follow-up \\ HCC, hepatocellular cancer \\ IQR, interquartile ranges \\ ITT, intention-to-treat \\ LRT, loco-regional treatment \\ LT, liver transplantation \\ MC, Milan Criteria \\ MELD, model for end-stage liver disease \\ MESIAH, Model to Estimate the Survival In Ambulatory patients with HCC \\ mRECIST, modified Response Evaluation Criteria in Solid Tumors \\ PR, partial response \\ $\mathrm{PD}, \quad$ progression disease \\ SD, $\quad$ stable disease \\ WL, waiting list \\ WT, waiting time
}

\section{Conflict of interest}

The authors have no conflicts of interest to declare in relation with this paper.

\section{Funds}

No funds were required for the present study.

\section{Contributors}

QL, AV and JL were responsible for the conception, design and analysis of the study and for writing the final report;

QL, AV, IS, AF, GM, GS, MHL, GV, TMM, DN, AWA and ACF were involved with the collection and interpretation of data;

UC, IG, MR, ET, GO, GME, GT and MV participated in data management and manuscript review. 


\begin{abstract}
The debate about the best approach to select patients with hepatocellular cancer (HCC) waiting for liver transplantation (LT) is still ongoing. This study aims to identify the best variables allowing to discriminate "high-" and "low-benefit" patients. To do so, the innovative concept of intention-totreat (ITT) survival benefit of LT has been created. Data of 2103 adult HCC patients consecutively enlisted during the period 1987-2015 were analyzed. Three rigorous statistical steps were used in order to create the ITT survival benefit of LT: the development of an ITT LT and a non-LT survival model, and the individual prediction of the ITT survival benefit of LT defined as the difference between the median ITT survival with (based on the first model) and without LT (based on the second model) calculated for each enrolled patient. Four variables (MELD, alpha-fetoprotein, Milan-Criteria status and radiological response) displayed a high effect in terms of delta-benefit. According to these risk factors, four benefit groups were identified. Patients with three-four factors ("no-benefit group", $n=405 / 2103 ; 19 \cdot 2 \%$ ) had no benefit of LT compared to alternative treatments. Inversely, patients without any risk factor ("large-benefit group", $\mathrm{n}=108 ; 5 \cdot 1 \%$ ) yielded the highest benefit from LT reaching 60 months. Conclusion: The here presented innovative ITT transplant survival benefit allows to better select HCC patients waiting for LT. The obtained stratification may lead to an improved and more equal way for organ allocation. Patients with no benefit should be delisted, whilst patients with large benefit ratio should be prioritized for LT.
\end{abstract}


Lai $Q$ et al. INTENTION-TO-TREAT SURVIVAL...

\section{INTRODUCTION}

The debate about the best approach for selecting patients with hepatocellular cancer (HCC) waiting for liver transplantation (LT) is still ongoing. Recent literature has shown that outcome of HCC patients in which the selection for LT is based on specific restrictive tumor characteristics may generate survival rates comparable to those obtained after LT in non-HCC patients. Furthermore, LT may also represent an optimal treatment for HCC patients harboring tumors being out of conventional (Milan) criteria if morphological and biological tumor behavior is taken into account. ${ }^{1}$ Consequently, the line between the need to justifiably transplant as many patients as possible and the necessity to select only patients having an effective benefit from LT is very thin and represents therefore an everyday clinical challenge.

Recently, the concept of "transplant benefit", corresponding to the number of years gained by LT minus the number of years offered by alternative treatments, has been proposed in the field of liver transplantation. $^{2}$ In the context of non-HCC patients, the concept of transplant benefit has been efficaciously adopted. Indeed, patients with a model for end-stage liver disease (MELD) score $<15$ do not improve their survival if transplanted or if staying on the waiting list (WL). ${ }^{2}$ When follow-up period is no longer than 10 years, transplant benefit estimation is equally influenced by pre- and post-LT variables, thus providing a balance between the concepts of pure urgency ("the sickest first") and pure utility (the highest survival gain). ${ }^{3}$

However, the definitive answer on the best pre- and post-LT variables to be used for selecting HCC patients able to reach an effective benefit from LT is still needed. Apart from morphological aspects, biological and "time-dependent" variables have been recently added in the LT selection process. ${ }^{4}$ Among them, waiting time (WT), alpha-fetoprotein (AFP) values and radiological response after neo-adjuvant loco-regional treatment (LRT) have been largely explored. ${ }^{5-9}$

Moreover, transplant benefit values have been always evaluated from the moment of LT and not from the moment of WL inclusion. In the present study, the innovative concept of intention-to-treat (ITT) transplant benefit has been proposed. ITT survival is defined as the LT survival from the 
Lai $Q$ et al. INTENTION-TO-TREAT SURVIVAL...

moment of patient enlistment and not from the day of LT, ${ }^{10}$ having been widely accepted in the LT community. ${ }^{11,12}$ The use of an ITT survival analysis allows the opportunity to analyze the results based on the initial treatment assignment and not on the treatment eventually received, thus avoiding various misleading artifacts and initial selection biases.

The aim of the present study is then to analyze a large multicenter European collaborative Project, with the intent to identify the best variables able to discriminate high or low benefit patients. In order to do so, an ITT survival benefit has been developed, aiming at identifying different patient subgroups deserving or not LT.

\section{MATERIALS AND METHODS}

A retrospective analysis of data from 2103 adult ( $\geq 18$ year-old) patients with radiological and/or pathological diagnosis of HCC was performed. All patients were listed for LT during the period from January 1, 1987 to December 31, 2015, and being dropped-out or undergoing a first LT during the same time period. Data were obtained from the prospectively collected databases of ten collaborative European Centers involved in the EURopean HEpatocellular CAncer and Liver Transplantation (EurHeCaLT) Project. The participating centers were Padua, Italy $(\mathrm{n}=346)$; Brussels, Belgium ( $\mathrm{n}=336)$; Innsbruck, Austria ( $\mathrm{n}=330)$; Sapienza University Rome, Italy ( $\mathrm{n}=243$ ); Royal Free London, UK ( $\mathrm{n}=193)$; Mainz, Germany ( $\mathrm{n}=176)$; San Camillo Hospital Rome, Italy $(\mathrm{n}=142)$; Tor Vergata University Rome, Italy $(\mathrm{n}=140)$; Ancona, Italy $(\mathrm{n}=110)$; and, Catholic University Rome, Italy $(\mathrm{n}=87)$.

Patients with incidental tumors, mixed hepatocellular-cholangiocellular tumors or cholangiocellular cancer misdiagnosed as HCC were excluded from the analysis.

Of note is that all of the participating centers do not consider anymore Milan Criteria (MC) as the limit for inscription on the WL: consequently, $636(30 \cdot 2 \%)$ MC-OUT patients were enlisted. Despite different policies were used in the different centers, all the transplanted cases reported were within University of San Francisco California Criteria, Up-to-seven Criteria or Tokyo ("5+10 role") 
Lai $Q$ et al. INTENTION-TO-TREAT SURVIVAL...

Criteria: so, the dimensional upper limit observed in the present study was $6.5 \mathrm{~cm}$ of diameter in the

target lesion and 10 nodules. A majority of patients $(n=1754 ; 83 \cdot 4 \%)$ had pre-LT multimodal LRT.

Such policy allowed an in-depth analysis of the response to LRT as a possible selection variable.

All analyzed patients were categorized in different groups according to the modified Response

Evaluation Criteria in Solid Tumors (mRECIST) criteria termed as Complete Response (CR),

Partial Response (PR), Stable Disease (SD) and Progression Disease (PD). ${ }^{10}$ Patients which did not have LRT were considered as no-LRT group: the decision to not consider no-LRT patients with a possible increase of the tumor burden before LT into the PD group derived from the consideration that these patients do not fully correspond from a biological point of view to patients with a tumor with a PD after a radiological treatment. In the treated patients, mRECIST status was defined after comparison between initial imaging at WL inscription and the last available one before LT or dropout (DO).

Patients listed before 1996 and 2010 were re-classified according to MC and mRECIST criteria according to the retrospective evaluation of their imagings. ${ }^{1,13}$

The adopted cut-offs of $1000 \mathrm{ng} / \mathrm{mL}$ and $15 \mathrm{ng} / \mathrm{mL} /$ month for AFP and AFP slope were selected according to literature data. ${ }^{6,7}$ The AFP slope was calculated using the two values at the moment of WL inscription and the one immediately before LT or DO. The adopted WT cut-off of 120 days and MELD cut-off of 13 were also chosen according to previous reports. ${ }^{5,11,14}$

Median patient follow-up (FU) from the moment of WL inscription was 3.7 years (interquartile ranges [IQR]: 1.4-7.6).

Statistical analysis

Continuous variables were reported as medians and IQR. Dummy variables were reported as numbers and percentages. Missing data relative to study covariates always involved less than $10 \%$ of patients. Thus, they were estimated using the Maximum Likelihood Estimation method. ${ }^{15}$ 
The statistical design of this study included three main steps: a) the development of an ITT LT survival model; b) the development of a non-LT survival model and; c) the individual prediction of the ITT survival benefit of LT defined as the difference between the median ITT survival with LT (based on the first model) and median survival without LT (based on the second model) calculated for each enrolled patient. The specific steps for the construction of the models are diffusely explained in Supplementary Data 1. We briefly reported here the statistical steps we adopted.

Firstly, the ITT LT survival model was constructed using a log-logistic model: the results of the model are reported in Supplementary Table 1. The obtained results of the model were applied to predict ITT median survival with LT of each enrolled patient.

Non-LT survival model was built starting from some assumptions: the majority of WL patients are censored by LT; ${ }^{16,17}$ median WT of HCC patients is relatively short, thus prediction of long-term survival of these patients may be inaccurate. ${ }^{5}$ Several statistical techniques have been proposed for resolving this problem. ${ }^{16-18}$ However, these methods are still insufficient to resolve the biases related to the complexity of WL dynamics, often requiring arbitrary corrections. ${ }^{18,19}$ The Model to Estimate the Survival In Ambulatory patients with HCC (MESIAH) was then adopted for resolving this problem. ${ }^{14}$ This model, recently validated both in western and eastern countries, ${ }^{20,21}$ provides a simple formula to translate the MESIAH score in individual survival predictions. Using patient characteristics at the last evaluation before LT or DO, we used the MESIAH score to simulate the median time to death that patients censored by LT would have had in the absence of LT. This simulated time to death was therefore used to perform a second log-logistic parametric survival model to find significant predictors of non-LT survival: the results of the model are reported in Supplementary Table 2. Then, we used this second model to predict non-LT median survival of each enrolled patient.

Finally, The ITT LT and the non-LT survival log-logistic models generated two median survival predictions for each enrolled patient. The ITT survival benefit of LT was, therefore, calculated for each patient as the difference between ITT LT median and the non-LT median survival estimations. 
All estimations were capped at 120 months, since this time horizon represents the ideal balance between utility and urgency allocation principles. ${ }^{4}$ A multivariate least square regression was finally used to find significant predictors of ITT LT benefit among studied variables. ${ }^{22,23}$ In all the multivariable survival models, all variables with $p<0.1$ at univariate model were included. In the final model only variables showing a significant impact on survival at the first multivariable model were maintained.

Since p-values can be biased from population size, results of survival benefit estimations in covariates subgroups were reported as effect size. Effect size is a standard measure that can be calculated from any number of statistical outputs. One type of effect size, the standardized mean effect, expresses the mean difference between two groups in standard deviation units. Typically, it is reported as Cohen's d, or simply referred to as d-value. ${ }^{24}$

Variables with a $p<0.05$ were considered statistically significant. The calculations were done with the JMP (1989-2003 SAS Institute Inc.) and Stata/IC 13.0 (1985-2013 StataCorp LP) packages.

\section{RESULTS}

Demographics of the entire population are displayed in Table 1. Two hundred forty-six $(11 \cdot 7 \%)$ of 2103 patients dropped-out during the WT period: $160 / 246(65 \cdot 0 \%)$ cases dropped-out due to HCC progression, with 143/246 (58.1\%) patients dying during the WT period. Looking more in detail the reasons of DO, 69 patients were excluded due to $\mathrm{HCC}$ progression (patient alive at the moment of DO). In 91 cases, a tumor-related death on WL was observed; 52 patients showed a liver diseaserelated death on WL, 25 moved to another center, and 9 were excluded due to poor compliance.

A total of 1857 patients underwent LT: $242(13 \cdot 0 \%)$ patients recurred. When considering the 1504 patients having a minimum FU of 1 year after LT, the recurrence rate was $16 \cdot 1 \%$.

After the construction of the different models, a multivariate least square regression analysis finally identified eight variables as significant predictors for ITT transplant benefit. Five variables favored an increase of benefit: age at listing $(\beta$-coefficient $=1 \cdot 3$; $p$-value $=0 \cdot 0006)$, MELD at LT or DO $(\beta$ - 
coefficient $=1 \cdot 1 ; \quad \mathrm{p}$-value $<0 \cdot 0001), \quad$ WT duration $\quad(\beta$-coefficient $=0 \cdot 1 ; \quad \mathrm{p}$-value $=0 \cdot 001), \quad$ last radiological HCC assessment of the major lesion diameter $(\beta$-coefficient $=10 \cdot 9 ; p$-value $<0 \cdot 0001)$, and of number of HCC lesions ( $\beta$-coefficient $=6 \cdot 5$; $p$-value $<0 \cdot 0001)$. In other terms, a higher benefit was reported in older patients, if MELD or WT increased, or if greater tumors were transplanted.

Three variables pointed towards a poor benefit: WL inscription before 2001 ( $\beta$-coefficient=-25·3; pvalue $<0 \cdot 0001)$, mRECIST PD $(\beta$-coefficient=-36.8; -value $<0 \cdot 0001)$, and last available $\operatorname{logAFP}$ value $(\beta$-coefficient $=-3 \cdot 4 ; p$-value $<0 \cdot 0001)$. In other terms, being listed before 2001, presence of radiological PD and progressive increase in AFP values were all linked to a poor benefit (Table 2).

ITT transplant benefit estimations in different clinically relevant subgroups were also looked at (Table 3). Five variables showed a moderate-to-high effect in terms of differences of median benefit: patients with last AFP value $\geq 1000 \mathrm{ng} / \mathrm{mL}$ (6.8 vs. 25.4 months in patients with AFP < $1000 \mathrm{ng} / \mathrm{mL}$; D-value=0.69), lab-MELD $\leq 13(19 \cdot 8$ vs. $39 \cdot 1$ months in patients with MELD > 13; D-value $=0 \cdot 81)$, mRECIST PD (10.6 vs. $29 \cdot 2$ months in patients without PD; D-value $=0 \cdot 78)$ and mRECIST CR $(7 \cdot 2 \mathrm{vs} \cdot 28 \cdot 7$ months in patients without CR; D-value $=0 \cdot 90)$ had very disappointing benefits. MC-IN status $(22 \cdot 8$ vs. $34 \cdot 5$ months in patients exceeding MC; D-value $=0 \cdot 47)$ and $\mathrm{WL}$ inscription before 2001 (10.4 vs. $27 \cdot 3$ months in patients enlisted after 2001; D-value=0.49) presented only a moderate benefit discrimination (Table 3, Figure 1).

Based on these results, it was firstly decided to exclude the period of transplantation from further analyses because it was considered as useless when applying to patients transplanted nowadays. When doing so, four benefit groups could be identified according to the presence of the remaining four risk factors. Patients presenting a combination of three to four factors (no benefit group: $\mathrm{n}=405 / 2103 ; 19 \cdot 2 \%$ ) had no benefit in being transplanted compared to alternative therapies (median value of improved survival: zero months). Patients in the small (two risk factors: $n=897 ; 42 \cdot 7 \%$ ) and moderate (one risk factor: $n=693 ; 33 \cdot 0 \%$ ) groups displayed improved survival benefits of 20 and 40 months, respectively. Conversely, patients without any risk factor (large benefit group: $\mathrm{n}=108 ; 5 \cdot 1 \%$ ) had the highest benefit reaching 60 months (Table 3, Figure 2). Different contour 
plots deriving from the combination of the different risk factors are displayed in Supplementary

\section{Figure 1.}

\section{DISCUSSION}

Twenty years after its introduction, MC are not anymore considered to be the best criterion to select HCC patients for $\mathrm{LT}^{25}$ However, the best compromise between the need to justifiably raise the number of transplantable patients and the necessity to minimize the risk for recurrence, without contemporaneously harming non-HCC patients on the WL, is still out. ${ }^{19}$

Aiming at squaring the circle, a recent paper by Mazzaferro interestingly reported that the only way to frame the complex scenario of LT for HCC is the ability to capture in a weighty manner tumor evolution in relation to its treatment, aiming to modulate scores able to estimate the risk of pre-LT DO and post-LT benefit. ${ }^{26}$ So, morphology "per se" is insufficient to optimize selection and allocation, and new criteria, possibly focused on "progression" instead than on static tumor characteristics should be used in order to better identify those patients in real need for LT. ${ }^{4}$

In Italy, a demanding effort has been made with the intent to build an algorithm based on the principles of urgency, utility and transplant benefit, clearly underlying the inequity of a purely MELD-based HCC allocation model. Different variables (response to LRT, WT, AFP) all have been advocated as possible selection criteria to be used in such a "benefit scenario". ${ }^{27}$ However, the main limit of their use in the setting of benefit is that no scientific evidence exists on their effective contribution in terms of survival.

In the present study, four different risk factors connected with poor ITT-benefit, have been identified: radiological progression/complete response, AFP increase, MC-IN status and low MELD score.

Several previously published studies corroborate our findings. The recent paper by Metha reported a selected population of HCC T2 patients waiting for LT with a very low 2-year probability of DO (only $1 \cdot 6 \%$ ). Tumor morphology (1 tumor of 2-3 cm), radiological response to LRT (complete 
response after the first treatment), and biological behavior (AFP level stably normal after the first LRT) selected these patients. ${ }^{28}$

Several European studies similarly confirmed the paramount role of radiological response, ${ }^{8,9,11}$ and AFP modification following LRT, ${ }^{6,7,11,18}$ as the better selection criterion of HCC patients awaiting LT. The multicentric EurHeCaLT study showed that the combination of radiological response and AFP slope allowed to better discriminate "low-risk" from "high-risk-for-recurrence" patients, and this independently from their MC-IN or OUT status. ${ }^{12}$. Two recent scores, all focusing on the HCC selection process, further underlined the importance of combining biology and morphology in order to further improve results. Interestingly, the TRAIN score, based on the combination of AFP slope, radiological progression, inflammatory markers and WT, was superior respect to $\mathrm{MC}$ in predicting patient death during the WT in a long-WT population, whilst it was superior in predicting post-LT recurrence in case of short $\mathrm{WT} .{ }^{11}$ The MORAL score, incorporating inflammatory markers, AFP and tumor morphology, also showed to be significantly superior to $\mathrm{MC}$, with an area under the curve of $0 \cdot 82$ vs. 0.63 for predicting post-LT HCC recurrence. ${ }^{29}$

Also the fact that MC-IN status was connected with poor survival benefit had been observed in a multicentre Italian study including 1328 patients: survival benefit was obtainable in patients having advanced HCC, and this was regardless of the "nodule number-size criteria" (as MC are) ${ }^{30}$ In other terms, the benefit increases when the number of nodules and the dimensions of the tumor contemporaneously increase, on the condition that radiological findings and AFP do not progress. Various articles already focused on the role of MELD increase as a cause of increased benefit. A US study clearly observed that the increase in MELD points corresponds to a progressive survival benefit increase in $\mathrm{HCC}$ and non-HCC patients, ranging from just a few months in patients with MELD score of 6-8 to 4 years in patients with MELD score of 36-40. ${ }^{19}$ Another Italian study similarly reported that MELD score increase was associated with a better benefit both in HCC and non-HCC patients; interestingly enough, this study observed that an equation based on the combination of MELD and AFP (the "HCC-MELD" equation) allowed the calculation of a 
numerical score for HCC patients, with the intent to calibrate their transplant benefit with the one observed in non-HCC patients having the same MELD value. ${ }^{18}$ This finding was also observed in the present series, in which MELD and AFP were factors allowing to discriminate low- and highbenefit patients.

Despite the fact that each risk factor has already been singularly investigated in other studies focusing on the prediction of survival in HCC patients, one should note that the present study presents several innovations. Firstly, a new concept of ITT survival benefit has been proposed, as well as a statistical methodology has been created for calculating it. The rationale for the proposal of this new concept is to further increase the balancing between pure priority and pure utility: the integration of two large populations of LT and non-LT patients in the creation of the ITT benefit statistical model allowed in fact to better calibrate the role of the evaluated variables in both settings.

Secondly, radiological response to LRT has been investigated for the first time in a benefit-related analysis. The lack of studies investigating its role in the LT selection process may be explained by the fact that several large cohorts include a smaller number of LRT cases compared to our series; moreover, radiological response has not been systematically collected in large populations, so until now only small mono-centre studies (apart the reported EurHeCaLT study) have been investigated. $^{12}$

Thirdly, this is the first time that all of the investigated variables have been connected in order to create different ITT benefit groups, and to define categories of patients that would benefit from LT. In fact, when three to four of the analyzed risk factors are present in a single patient, ITT benefit was nil. Such a result is extremely important, because patients presenting three to four risk factors represented $19 \%$ of the investigated population. Interestingly enough, this specific "no benefit" group consisted of two main patient categories. On one side, MC-IN patients with low MELD showing radiological-biological progression were observed. These patients are similar to those 
patients already reported in the study by Metha, in which poor radiological response and increased AFP corresponded to higher percentages of DO. ${ }^{28}$

On the other hand, MC-IN patients with low MELD with complete radiological response corresponded to the Transplantable Tumor (TT)0 category reported by Mazzaferro, in which the cancer is "zeroed" by LRT/resection during the WT. ${ }^{26}$ In both scenarios such patients should be delisted: in the first case because of the poor benefit connected with an advanced cancer, in the second case due to a poor benefit associated with a completely healed tumor.

Conversely, when looking at the "high" ITT benefit group, an extraordinary benefit (5 years) in comparison to not-transplanted patients presenting the same characteristics was observed. As a consequence, it looks obvious that such a patient population should be surely considered for LT. Despite the fact that this group consists of high-MELD MC-OUT patients (without any evidence of radiological-biological progression), thus potentially being associated with more peri-operative mortality and post-LT recurrence, the benefit in transplanting (and even prioritizing) them is clear. Moreover, it should be underlined that such a population is really small, representing no more than $5 \%$ of the entire investigated population. Therefore, prioritization of such a population should only marginally impact on the number of used grafts, mainly if we consider on the opposite the great number of potentially "preservable" livers if we delist the patients with no ITT benefit (as a reminder, this group represents $19 \%$ of all the investigated cases!).

When considering the group of patients presenting "low" ITT benefit (patients with two risk factors: 20 months of benefit), one should keep in mind that the decision to transplant these patients has to be seen in the context of the opportunity to perform a LT without harming the group of listed nonHCC patients ("concept of equity"). ${ }^{31}$ Such a concept has been very elegantly demonstrated by Volk in the US population, in which the decision to transplant an HCC patient was justified only if a minimal survival threshold was reached: only in this case, in fact, the benefit of transplanting tumor patients outweighed the harm for not transplanting non-HCC patients. ${ }^{32}$ Similar results were also reported in a monocentre experience from Italy. ${ }^{33}$ As a consequence, patients presenting only 
small benefit (corresponding to $42 \cdot 7 \%$ of our entire investigated population) should be carefully considered, mainly when evaluated in a low-volume center. As an example, a MC-OUT patient with low MELD and AFP $\geq 1000 \mathrm{ng} / \mathrm{mL}$ should be closely evaluated in a low-volume centre in light of his high recurrence risk.

The present study did not explore the opportunity to propose a more equal organ allocation model among enlisted HCC and non-HCC patients in terms of priority score for LT, such the "HCCMELD" model did. ${ }^{18}$ Moreover, this latter score is based only on AFP and MELD and it was calculated only in T2 HCC patients, whilst the present score presents a higher complexity (AFP, MELD, radiological response, initial MC status). The development of an equation able to recalibrate the whole allocation process (i.e. including both selection of patients for listing and prioritization of listed patients) among non-HCC and HCC patients should be further explored.

The authors admit that the present study has some limitations. First of all, it is a retrospective collaborative non-randomized study covering 30-year period. Consequently, some statistical and methodological limits exist. However, we feel confident that the largeness of the investigated population and the rigorous adherence to the statistical analysis guidelines may have counteracted these negative parameters. Moreover, the introduction of the period of WL inscription as covariate in the multivariate models further minimizes the possible errors deriving from a "period-dependent" selection.

Another possible limit derives from the fact that allocation disparities may be caused by not investigated parameters other than tumor characteristics (i.e., blood group): unfortunately, the retrospective character of the present study did not give the opportunity to fully investigate such aspects.

\section{CONCLUSIONS}

The innovative ITT survival benefit of LT allows to better discriminate HCC patients waiting for LT in relation to their real need for transplantation. Such a stratification may lead to an improved 
and more equitable liver allocation. New aspects such as radiological response after LRT should be implemented in clinical practice as a selection parameter to be used in HCC patients. The combination of radiological and biological tumor characteristics should be considered as the gold standard for HCC selection instead of the conventionally used "only morphological" criteria. 


\section{EurHeCaLT Study Group Collaborators}

Austria: Lehner K (Medical University Innsbruck, Innsbruck);

Belgium: Rico Juri JM (Catholic University of Louvain, Brussels);

Germany: Heise M (University of Mainz, Mainz);

Italy: dalla Bona E (University of Padua, Padua); Melandro F (Sapienza University, Rome); Levi

Sandri GB (San Camillo Hospital, Rome); Baiocchi L (Tor Vergata University, Rome);

Mocchegiani F (Ancona University, Ancona); Bianco G (Catholic University, Rome);

UK: Onali S (UCL Institute for Liver and Digestive Health and Royal Free Sheila Sherlock Liver Centre, Royal Free Hospital and UCL, London). 


\section{REFERENCES}

1. Mazzaferro V, Llovet JM, Miceli R, Bhoori S, Schiavo M, Mariani L, et al.; Metroticket Investigator Study Group. Predicting survival after liver transplantation in patients with hepatocellular carcinoma beyond the Milan criteria: a retrospective, exploratory analysis. Lancet Oncol 2009; 10:35-43.

2. Merion RM, Schaubel DE, Dykstra DM, Freeman RB, Port FK, Wolfe RA. The survival benefit of liver transplantation. Am J Transplant 2005;5:307-13.

3. Vitale A, Volk M, Cillo U. Urgency, utility, and time horizon of transplant benefit. Liver Transpl $2015 ; 21: 565-6$.

4. Lai Q, Lerut JP. Hepatocellular cancer: how to expand safely inclusion criteria for liver transplantation. Curr Opin Organ Transplant 2014;19:229-34.

5. Samoylova ML, Dodge JL, Yao FY, Roberts JP. Time to transplantation as a predictor of hepatocellular carcinoma recurrence after liver transplantation. Liver Transpl 2014;20:937-44.

6. Duvoux C, Roudot-Thoraval F, Decaens T, Pessione F, Badran H, Piardi T, et al.; Liver Transplantation French Study Group. Liver transplantation for hepatocellular carcinoma: a model including $\alpha$-fetoprotein improves the performance of Milan criteria. Gastroenterology 2012;143:986-94.

7. Vibert E, Azoulay D, Hoti E, Iacopinelli S, Samuel D, Salloum C, et al. Progression of alphafetoprotein before liver transplantation for hepatocellular carcinoma in cirrhotic patients: a critical factor. Am J Transplant 2010;10:129-37.

8. Otto G, Schuchmann M, Hoppe-Lotichius M, Heise M, Weinmann A, Hansen T, et al. How to decide about liver transplantation in patients with hepatocellular carcinoma: size and number of lesions or response to TACE? J Hepatol 2013;59:279-84. 
9. Finkenstedt A, Vikoler A, Portenkirchner M, Mülleder K, Maglione M, Margreiter C, et al. Excellent post-transplant survival in patients with intermediate stage hepatocellular carcinoma responding to neoadjuvant therapy. Liver Int 2016;36:688-95.

10. Llovet JM, Fuster J, Bruix J. Intention-to-treat analysis of surgical treatment for early hepatocellular carcinoma: resection versus transplantation. Hepatology 1999;30:1434-40.

11. Lai Q, Nicolini D, Inostroza Nunez M, Iesari S, Goffette P, Agostini A, et al. A novel prognostic index in patients with hepatocellular cancer waiting for liver transplantation. TimeRadiological-response-Alpha-fetoprotein-INflammation (TRAIN) score. Ann Surg 2016;264:78796.

12. Lai Q, Avolio AW, Graziadei I, Otto G, Rossi M, Tisone G, et al.; European Hepatocellular Cancer Liver Transplant Study Group. Alpha-fetoprotein and modified response evaluation criteria in solid tumors progression after locoregional therapy as predictors of hepatocellular cancer recurrence and death after transplantation. Liver Transpl 2013;19:1108-18.

13. Lencioni R, Llovet JM. Modified RECIST (mRECIST) assessment for hepatocellular carcinoma. Semin Liver Dis 2010;30:52-60.

14. Yang JD, Kim WR, Park KW, Chaiteerakij R, Kim B, Sanderson SO, et al. Model to estimate survival in ambulatory patients with hepatocellular carcinoma. Hepatology 2012;56:614-21.

15. Baraldi AN, Enders CK. An introduction to modern missing data analyses. J Sch Psychol 2010; 48: 5-37.

16. Schaubel DE, Guidinger MK, Biggins SW, Kalbfleisch JD, Pomfret EA, Sharma P, et al. Survival benefit-based deceased-donor liver allocation. Am J Transplant 2009;9:970-81.

17. Toso C, Dupuis-Lozeron E, Majno P, Berney T, Kneteman NM, Perneger T, et al. A model for dropout assessment of candidates with or without hepatocellular carcinoma on a common liver transplant waiting list. Hepatology 2012;56:149-56.

18. Vitale A, Volk ML, De Feo TM, Burra P, Frigo AC, Ramirez Morales R, et al.; Liver Transplantation North Italy Transplant program (NITp) working group. A method for establishing 
allocation equity among patients with and without hepatocellular carcinoma on a common liver transplant waiting list. J Hepatol 2014;60:290-7.

19. Berry K, Ioannou GN. Comparison of liver transplant-related survival benefit in patients with versus without hepatocellular carcinoma in the United States. Gastroenterology 2015;149:669-80. 20. Farinati F, Vitale A, Spolverato G, Pawlik TM, Huo TL, Lee YH, et al.; ITA.LI.CA study group. Development and validation of a new prognostic system for patients with hepatocellular carcinoma. PLoS Med 2016;13:e1002006.

21. Kim BH, Park JW, Nam BH, Kwak HW, Kim WR. Validation of a model to estimate survival in ambulatory patients with hepatocellular carcinoma: a single-centre cohort study. Liver Int 2014;34:e317-23.

22. Jacob M, Lewsey JD, Sharpin C, Gimson A, Rela M, van der Meulen JH. Systematic review and validation of prognostic models in liver transplantation. Liver Transpl 2005;11:814-25.

23. Kalil AC, Mattei J, Florescu DF, Sun J, Kalil RS. Recommendations for the assessment and reporting of multivariable logistic regression in transplantation literature. Am J Transplant 2010; 10: $1695-1703$.

24. Burnand B, Kernan WN, Feinstein AR. Indexes and boundaries for "quantitative significance" in statistical decisions. J Clin Epidemiol 1990; 43: 1273-84.

25. Levi Sandri GB, Guerra F, Lai Q. Twenty years of Milan criteria: the wicked flee though no one pursues. Hepatobiliary Surg Nutr 2016;5:377-8.

26. Mazzaferro V. Squaring the circle of selection and allocation in liver transplantation for HCC: An adaptive approach. Hepatology 2016;63:1707-17.

27. Cillo U, Burra P, Mazzaferro V, Belli L, Pinna AD, Spada M, et al.; I-BELT (Italian Board of Experts in the Field of Liver Transplantation). A multistep, consensus-based approach to organ allocation in liver transplantation: toward a "blended principle model". Am J Transplant $2015 ; 15: 2552-61$. 
28. Mehta N, Dodge JL, Goel A, Roberts JP, Hirose R, Yao FY. Identification of liver transplant candidates with hepatocellular carcinoma and a very low dropout risk: implications for the current organ allocation policy. Liver Transpl 2013;19:1343-53.

29. Halazun KJ, Najjar M, Abdelmessih RM, Samstein B, Griesemer AD, Guarrera JV, et al. Recurrence after liver transplantation for hepatocellular carcinoma: a new MORAL to the story. Ann Surg 2017; 265: 557-64.

30. Vitale A, Morales RR, Zanus G, Farinati F, Burra P, Angeli P, et al.; Italian Liver Cancer group. Barcelona Clinic Liver Cancer staging and transplant survival benefit for patients with hepatocellular carcinoma: a multicentre, cohort study. Lancet Oncol 2011;12:654-62.

31. Vitale A, Volk M, Cillo U. Transplant benefit for patients with hepatocellular carcinoma. World J Gastroenterol 2013;19:9183-8.

32. Volk ML, Vijan S, Marrero JA. A novel model measuring the harm of transplanting hepatocellular carcinoma exceeding Milan criteria. Am J Transplant 2008;8:839-46.

33. Vitale A, Volk ML, Gambato M, Zanus G, D'Amico F, Carraro A, et al. Estimation of the harm to the waiting list as a crucial factor in the selection of patients with hepatocellular carcinoma for liver transplantation. Transplant Proc 2010;42:1194-6. 


\section{FIGURES}

Figure 1. Benefit risk factors and benefit gains. For each of the 9 reported risk factors (section A), two median benefits are reported according to specific threshold values (section B). Median benefit gains are calculated for each factor by difference between the reported median benefits (section C). Benefit gains are arbitrary grouped in 4 levels (very small, small, moderate and large benefit).

Figure 2. Incidence of the 4 different "Benefit Groups" in the examined population. 
Brussels, 18 November, 2016

Dear Editor,

We hereby submit our original manuscript entitled "INTENTION-TO-TREAT SURVIVAL BENEFIT OF LIVER TRANSPLANTATION IN PATIENTS WITH HEPATOCELLULAR CANCER”

We report a retrospective analysis of data coming from 2103 adult patients with hepatocellular cancer (HCC) enlisted for liver transplantation (LT) during the period 1987-2015. Data were obtained from the prospectively collected databases of ten collaborative European Centers involved in the EURopean HEpatocellular CAncer and Liver Transplantation (EurHeCaLT) Project.

The present study, based on a sophisticated statistical analysis, introduces the innovative concept of intention-to-treat (ITT) survival benefit of LT.

This new selection tool allowed to better select HCC patients waiting for LT. Four groups presenting different benefit gains were then identified, thus leading to an improved and more equal way for organ allocation. In fact, patients with no benefit ratio should be de-listed, whilst patients with large benefit ratio should be prioritized for LT.

We are of the opinion that the present paper represents an added value to surgeons, oncologists, and mainly gastroenterologists and transplant physicians dealing with HCC and indication or prioritization for LT.

All authors participated in the intellectual content, conception and design of the paper, took public responsibility for it and have agreed to have their name listed as contributors. Neither this manuscript nor parts of it have been previously submitted for publication.

None of the authors received any financial interest, direct or indirect, related to the achievement of this work.

If requested by the editors, we will provide the data and information on which the results of this manuscript are based.

We hope that this paper can be accepted for publication in the HEPATOLOGY Journal.

Sincerely Yours

Quirino LAI, MD PhD

Corresponding author 


\section{HEP-16-2270 \\ INTENTION-TO-TREAT SURVIVAL BENEFIT OF LIVER TRANSPLANTATION IN PATIENTS WITH HEPATOCELLULAR CANCER}

We thank the Editors of HEPATOLOGY for having the opportunity to revise the article with the intent to improve its quality. We hope the revision work will be able to fully satisfy the requests of the reviewers.

\section{Reviewer: 1}

We really thank the reviewer for the statistical suggestions and comments. To better answer to his/her issues, we have performed a complete statistical revision of our study with the help of an expert Statistician from Padua University.

Lai et al. are proposing a transplant benefit model based on intention-to-treat (ITT) to assess the number of life years gained/lost by transplanting patients with HCC. They suggest that ideal candidate for transplant (with the highest transplant benefit) have high MELD $(>13)$, reasonable AFP $(<1000)$, no progressive disease/complete response, and are outside Milan.

The concept is of interest, and represents a further adaptation from previous data. The proposed model cannot be considered as final, but it helps understanding the expected benefit from transplant in specific patients. The article is well written.

1) One of the originality of the model is the ITT concept, and I would suggest better highlighting this point, by better explaining the current model versus previous ones (especially the one in Vitale et al. J Hepatology 2014).

ANSWER. We thank the reviewer for this important comment giving us the possibility to better explain these important concepts. The following sentence has been added in the Introduction section of the paper: "Moreover, transplant benefit values have been always evaluated from the moment of LT and not from the moment of WL inclusion. In the present study, the innovative concept of intention-to-treat (ITT) transplant benefit has been proposed. ITT survival is defined as the LT survival from the moment of patient enlistment and not from the day of LT, having been widely accepted in the LT community. The use of an ITT survival analysis allows the opportunity to analyze the results based on the initial treatment assignment and not on the treatment eventually received, thus avoiding various misleading artifacts and initial selection biases."

Regarding to the model by Vitale et al., it was actually proposed with the intent to create a more equal organ allocation among enlisted HCC and non-HCC patients in terms of priority score for LT. The present study did not explore such an aspect, focusing on the detection of variables able to discriminate among high-benefit and low-benefit HCC patients and on the definition of the challenging clinical decision about the patients to include vs. to exclude from the WL. The "HCC-MELD" score proposed by Vitale et al. is based only on AFP and MELD and it was calculated only in T2 HCC patients, whilst the present score presents a higher complexity (AFP, MELD, radiological response, initial MC status).

A sentence has been added in the Discussion section of the paper:

"The present study did not explore the opportunity to propose a more equal organ allocation model among enlisted HCC and non-HCC patients in terms of priority score for LT, such the "HCC-MELD" model did. Moreover, this latter score is based only on AFP and MELD and it was calculated only in T2 HCC patients, whilst the present score presents a higher complexity (AFP, MELD, radiological response, initial MC status). The development of an equation able to recalibrate the whole allocation process (i.e. including both selection of patients for listing and prioritization of listed patients) among non-HCC and HCC patients should be further explored." 
2) Please provide the number of missing data for each studied variable (potentially in Table 1). How were they handled?

ANSWER. We really thank the reviewer for this comment because we actually forgot to specify one important aspect of our statistical analysis in the methods.

"Missing data relative to study covariates always involved less than 10\% of patients. Thus, they were estimated using the Maximum Likelihood Estimation method."

A reference was added accordingly: Baraldi AN, Enders CK. An introduction to modern missing data analyses. Journal of school psychology 2010; 48(1): 5-37.

3) Figure 2 suggests that patients without LRT have no risk factor, yet they could still present a PD. Please explain and expand.

ANSWER. We agree with the reviewer. However, when we defined PD or CR, we only considered the cases with an effective post-treatment radiological response accordingly to the mRECIST criteria. These criteria have been defined in accordance with the effective biological-morphological tumor response evaluable at radiological assessment after any type of therapy (LRT, chemotherapy, sorafenib). In case of no treatment, the possible increase of the tumor eventually represents its natural evolution, however not fully corresponding from a biological point of view to a tumor with a PD after a treatment. Moreover, in the great majority of cases, no-LRT cases presented a "fast-track" approach with short WT, thus impeding the "factor time" to select tumors with an effective tumor dimensional increase.

We Added the following sentence in Material and Methods with the intent to explain this concept:

"the decision to not consider no-LRT patients with a possible increase of the tumor burden before LT into the PD group derived from the consideration that these patients do not fully correspond from a biological point of view to patients with a tumor with a PD after a radiological treatment."

4) The authors state that "participating centers do not consider Milan Criteria as the limit". Please be more precise. Which selection criteria were used? In addition, and on a similar note, the best ITT benefit was achieved in patients MC-OUT. Please be more precise in the description of the Milan out patients. How far can we go beyond Milan? Size? Number?

ANSWER. We added in Table 1 information about the number of cases exceeding UCSFC, up-to-seven and Tokyo (" $5+10$ role") criteria. Only 76 on 2103 (0.4\%) patients contemporaneously exceeding all of these three criteria were eventually transplanted: all of these were transplanted before the introduction of $M C$ or were transplanted in Padua centre, in which morphological aspects are no more used as selection tools but only biological features are commonly used for HCC selection.

In Materials and Methods, we added the following sentence:

"Despite different policies were used in the different centers, all the transplanted cases reported were within University of San Francisco California Criteria, Up-to-seven Criteria or Tokyo ("5+10 role") Criteria: so, the dimensional upper limit observed in the present study was $6.5 \mathrm{~cm}$ of diameter in the target lesion and 10 nodules."

5) "160/246 (65.0\%) cases dropped-out due to HCC progression". Please specify why the other patients dropped-out. Did some patients improve/moved to another center? How were they handled?

ANSWER. We added in Results the following sentence:

"Looking more in detail the reasons of DO, 69 patients were excluded due to HCC progression (patient alive at the moment of DO). In 91 cases, a tumor-related death on WL was observed; 52 patients showed a liver disease-related death on WL, 25 moved to another center, and 9 were excluded due to poor compliance." 
6) How can an increased age be associated with an improved transplant survival (page 8)? This would mean that older patients should be favored compared to younger one. Please expend, and comment.

ANSWER. We thank the reviewer for this comment. Actually, the data reported show that increased age was connected with an increased benefit, not an increased post-LT survival. In other terms, older patients obtained a higher benefit in being transplanted respect to being treated with other therapies respect to younger patients. However, when the cut-off value of $\geq 60$ years of listing was used, a very small benefit of only 2 months was observed. So, the impact of such a result was neglectable and we decided not to describe it in discussion.

7) The fact that the year of WL inscription has an impact on the transplant benefit suggests that practices/outcomes have changed over time, and that the proposed conclusions may not reflect current practice. Simply adding this variable in the multivariable model does not appear enough. Please use a more homogeneous population, covering a more restricted period.

ANSWER. We thank again the reviewer for this comment. With the intent to appropriately correct our study in light of the suggestions of the Reviewers, we performed a complete statistical revision of our study with the help of an expert Statistician from Padua University.

As suggested by the reviewer, we performed new multivariable models only evaluating patients listed after 01/01/2001 $(n=1,802)$.

As you can see in new supplementary tables 3 and 4, variables estimates obtained from multivariable models (i.e. for ITT LT survival, non-LT survival, and benefit) resulted very similar to that of the whole population (Table 2, suppl. Tables 1, 2). This sub-analysis gave us, therefore, a strong statistical demonstration that the introduction of the variable "period of $L T$ " in all the multivariable models $(n=2,103)$ of the first version of the paper effectively represented a guarantee of solid statistical approach.

\section{Reviewer: 2}

We really thank the reviewer for the positive comments. To better answer to his/her issues, we have performed a complete statistical revision of our study with the help of an expert Statistician from Padua University.

1) Statistical methods must be checked by a statistician

ANSWER. As suggested, we performed a complete statistical revision of our study with the help of an expert Statistician from Padua University.

2) It is not clear which is the study-period: 1984-2015 (abstract) or 1987-2015 (Materials and Methods).

ANSWER. We are sorry for this error. The first enlisted patient with the diagnosis of HCC was listed on February $12^{\text {th }}, 1987$. We have corrected the error in the abstract.

\section{Reviewer: 3}

We really thank the reviewer for the statistical suggestions and comments. To better answer to his/her issues, we have performed a complete statistical revision of our study with the help of an expert Statistician from Padua University. 
1) Although the term "intention to treat" is well recognized in the clinical trial and statistical literature, it is not as common a term in observational designs. Please clarify in lay terms what is meant by ITT survival benefit during the introduction.

ANSWER. The following sentence has been added in the Introduction section of the paper:

"Moreover, transplant benefit values have been always evaluated from the moment of LT and not from the moment of WL inclusion. In the present study, the innovative concept of intention-to-treat (ITT) transplant benefit has been proposed. ITT survival is defined as the LT survival from the moment of patient enlistment and not from the day of LT, having been widely accepted in the LT community. The use of an ITT survival analysis allows the opportunity to analyze the results based on the initial treatment assignment and not on the treatment eventually received, thus avoiding various misleading artifacts and initial selection biases."

2) Methods: Please define the term MC-OUT ( $\mathrm{p} 6$ line 40).

ANSWER. According to the suggestions already reported by Reviewer 1, we added in Table 1 information about the number of cases exceeding UCSFC, up-to-seven and Tokyo (" $5+10$ role") criteria. Only 76 on $2103(0.4 \%)$ patients contemporaneously exceeding all of these three criteria were eventually transplanted: all of these were transplanted before the introduction of MC or were transplanted in Padua centre, in which morphological aspects are no more used as selection tools but only biological features are commonly used for HCC selection.

In Materials and Methods, we added the following sentence:

"Despite different policies were used in the different centers, all the transplanted cases reported were within University of San Francisco California Criteria, Up-to-seven Criteria or Tokyo ("5+10 role") Criteria: so, the dimensional upper limit observed in the present study was $6.5 \mathrm{~cm}$ of diameter in the target lesion and 10 nodules."

3) The MESIAH score was used to simulate time to death in patients that were censored by LT. The simulated additional time they would have lived in absence of LT was then summed with their wl time. Given that this was essentially a missing data problem, there is uncertainty in this value from the imputation. Rather than giving this imputed value the same weight as an actual observed value, the imputation process should account for this uncertainty. Multiple imputation would be one way to account for this.

ANSWER. We understand the perplexities of the reviewer concerning our non-LT survival model. However, using a real HCC population waiting LT to predict long-term survival represents a great (and probably not solvable) statistical problem because the high proportion of patients censored for LT at a very low median time from listing as underlined in detail in the supplementary text.

Also the expert statistician from Padua University now reviewing our data confirmed that this peculiarity of waiting list populations cannot be resolved as a missing data imputation problem for some main reasons:

1. of the cohort of 2,103 patients included, 1,894 had the LT at a median time of 5.2 months from listing (90\% censoring);

2. the reason for censoring is informative rather than not informative, while missing data are supposed to be at random.

For these reasons, we afforded the problem using the best predictive survival model for HCC patients (i.e. the MESIAH score) simulating the survival of patients if had they not been transplanted.

We sincerely hope that the reviewer could accept this original but also unavoidably biased methodological aspect of this study. The aim of this study is not to give extremely precise estimations of LT survival benefit, but only to obtain a qualitative stratification of the HCC population in different 
subgroups (i.e. no, small, moderate, high benefit) in order to help clinicians in selecting HCC patients for LT according to the innovative ITT transplant benefit principle.

4) Is the multivariate least squares regression a linear regression?

ANSWER. Yes, it was.

5) Please describe the steps for determining the significant factors in the multivariable analysis of survival benefit. Provide clarity on the census of variables considered for the multivariable model and be specific as to how the variables were selected for inclusion. (E.g. where they based on a univariate screening process followed by inclusion of all significant factors in the model or some other selection procedure?).

ANSWER. We really thank the reviewer for this comment underlying a missing aspect of our original methods section. In the original paper, in fact, this explanation was only written below supplementary tables. We now specified also in the methods that:

"In all the multivariable survival models, all variables with $p<0.1$ at univariate model were included. In the final model only variables showing a significant impact on survival at the first multivariable model were maintained."

6) Specify the units of survival benefit in table 2.

ANSWER. We now specified that the units of survival benefit were months.

7) Please describe what the d-value is and how it's calculated in the methods.

ANSWER. Again, we thank the reviewer for this comment giving us the possibility to better explain our methods. We now specified that:

"Since p-values can be biased from population size, results of survival benefit estimations in covariates subgroups were reported as effect size. Effect size is a standard measure that can be calculated from any number of statistical outputs. One type of effect size, the standardized mean effect, expresses the mean difference between two groups in standard deviation units. Typically, it is reported as Cohen's $d$, or simply referred to as d-value."

$A$ new reference was added accordingly: Burnand B, Kernan WN, Feinstein AR. Indexes and boundaries for "quantitative significance" in statistical decisions. J Clin Epidemiol 1990; 43: 1273-84.

8) Can confidence intervals be added to the effect size (d-values) estimates in table 3 ?

ANSWER. As requested, we added 95\% confidence intervals in Table 3. 
Lai $Q$ et al. INTENTION-TO-TREAT SURVIVAL...

TABLES

Table 1. Patient- and tumor-related characteristics in the EURHECALT study population.

\begin{tabular}{|c|c|}
\hline Variables & $\begin{array}{l}\text { Study group (n=2103) } \\
\text { Median (IQR) or n (\%) }\end{array}$ \\
\hline Period of WL inscription (1987-2000 vs. $2001-2015)$ & $301 / 1802(14 \cdot 3 / 85 \cdot 7)$ \\
\hline $\begin{array}{l}\text { WT days } \\
\geq 120 \text { days }\end{array}$ & $\begin{array}{c}137(57-284) \\
963(45 \cdot 8)\end{array}$ \\
\hline Male gender & $1763(83 \cdot 8)$ \\
\hline $\begin{array}{l}\text { Recipient age at WL inscription (years) } \\
\geq 60 \text { years }\end{array}$ & $\begin{array}{c}56 \cdot 8(49 \cdot 7-62 \cdot 0) \\
731(34 \cdot 8) \\
\end{array}$ \\
\hline $\begin{array}{l}\text { Cause of underlying cirrhosis }\left(^{*}\right) \\
\text { HCV } \\
\text { HBV } \\
\text { Alcohol }\end{array}$ & $\begin{array}{l}1001(47 \cdot 6) \\
391(18 \cdot 6) \\
631(30 \cdot 0)\end{array}$ \\
\hline $\begin{array}{l}\text { Laboratory MELD at LT or DO } \\
\text { MELD } \leq 13\end{array}$ & $\begin{array}{c}12(9-16) \\
1395(66 \cdot 3)\end{array}$ \\
\hline Laboratory albumin $(\mathrm{g} / \mathrm{dl})$ at $\mathrm{LT}$ or DO & $4 \cdot 0(3 \cdot 8-4 \cdot 0)$ \\
\hline $\begin{array}{l}\text { HCC at WL inscription } \\
\text { Major lesion diameter }(\mathrm{cm}) \\
\text { Number of lesions } \\
\text { MC-OUT status }\end{array}$ & $\begin{array}{c}3 \cdot 0(2 \cdot 0-4 \cdot 0) \\
2(1-3) \\
636(30 \cdot 2)\end{array}$ \\
\hline $\begin{array}{l}\text { Last radiological HCC assessment } \\
\text { Major lesion diameter }(\mathrm{cm}) \\
\text { Number of lesions } \\
\text { MC-OUT status } \\
\text { University of San Francisco California Criteria status } \\
\text { Up-to-seven Criteria status } \\
\text { Tokyo Criteria (" } 5+10 \text { role") status }\end{array}$ & $\begin{array}{l}2 \cdot 0(0 \cdot 0-3 \cdot 0) \\
1(1-3) \\
476(22 \cdot 6) \\
349(16 \cdot 6) \\
253(12 \cdot 0) \\
114(5 \cdot 4)\end{array}$ \\
\hline $\begin{array}{l}\text { LRT }(* *) \\
\text { Total number of procedures } \\
\text { Complete response } \\
\text { Progressive disease }\end{array}$ & $\begin{array}{c}1754(83 \cdot 4) \\
2(1-3) \\
380(18 \cdot 1) \\
491(23 \cdot 3) \\
\end{array}$ \\
\hline $\begin{array}{l}\text { AFP } \\
\text { At listing (ng/mL) § } \\
\text { Last available AFP (ng/mL) } \\
\geq 1000 \mathrm{ng} / \mathrm{mL} \\
\text { Slope } \geq 15 \mathrm{ng} / \mathrm{mL} / \mathrm{month} \S\end{array}$ & $\begin{array}{c}10 \cdot 0(4 \cdot 8-37 \cdot 3) \\
9 \cdot 7(4 \cdot 4-34 \cdot 9) \\
63(3 \cdot 0) \\
228(12 \cdot 6) \\
\end{array}$ \\
\hline $\begin{array}{l}\text { DO } \\
\text { HCC-related DO } \\
\text { Death during WT }\end{array}$ & $\begin{array}{l}246(11 \cdot 7) \\
160(7 \cdot 6) \\
143(6 \cdot 8)\end{array}$ \\
\hline $\begin{array}{l}\text { Recurrence }(* * *) \\
\text { Within } 1 \text { year after LT } \\
\text { Within } 2 \text { years after LT } \\
\text { Within } 3 \text { years after LT } \\
\text { Within } 5 \text { years after LT }\end{array}$ & $\begin{array}{c}242 / 1504(16 \cdot 1) \\
76 / 1504(5 \cdot 1) \\
138 / 1504(9 \cdot 2) \\
172 / 1504(11 \cdot 4) \\
213 / 1504(14 \cdot 2)\end{array}$ \\
\hline \multicolumn{2}{|c|}{$\begin{array}{l}\left.{ }^{*}\right) \text { multiple causes in the same patient: } \mathrm{HCV}+\text { alcohol }=101 ; \mathrm{HCV}+\mathrm{HBV}=29 ; \mathrm{HBV}+\text { alcohol }=22 ; \mathrm{HCV}+ \\
\mathrm{HBV}+\text { alcohol }=6 ; \text { alcohol }+ \text { other }=6 ; \mathrm{HCV}+\text { other cause }=5 ; \text { alcohol }+\mathrm{NASH}=5 ; \mathrm{HCV}+\text { alcohol }+ \text { other } \\
\text { cause }=3 ; \mathrm{HBV}+\text { other cause }=3 ; \mathrm{HCV}+\mathrm{HBV}+\text { alcohol }+\mathrm{NASH}=1 . \\
(* *) \text { percentages calculated only on patients undergoing LRT. } \\
\left(\begin{array}{l}* * *) \\
\text { percentages calculated only on transplanted patients with } \mathrm{FU}>1 \text { year. }\end{array}\right. \\
\S \text { medians, IQR and percentages calculated on } 1804(85 \cdot 8 \%) \text { cases with available data. }\end{array}$} \\
\hline
\end{tabular}


Abbreviations: WT, waiting time, IQR, interquartile ranges; WL, waiting list; HCV, hepatitis C virus; HBV, hepatitis B virus; NASH, non-alcoholic steato-hepatitis; MELD, model for end-stage liver disease; LT, liver transplantation; DO, drop-out HCC, hepatocellular cancer; MC, Milan Criteria; LRT, loco-regional treatment; AFP, alpha-fetoprotein; FU, follow-up.

Table 2. Multivariate least square regression evaluating significant predictors of ITT transplant benefit.

\begin{tabular}{|l|c|c|}
\hline \multirow{2}{*}{ Variables } & \multicolumn{2}{|c|}{ Multivariable model } \\
\cline { 2 - 3 } & $\begin{array}{c}\text { Coefficient } \pm \text { SE } \\
\text { (months) }\end{array}$ & p value \\
\hline Constant & $-14 \cdot 7 \pm 2 \cdot 7$ & $<0 \cdot 0001$ \\
\hline WL inscription before 2001 & $-25 \cdot 3 \pm 1 \cdot 0$ & $<0 \cdot 0001$ \\
\hline Age at listing (per year) / 10 & $1 \cdot 3 \pm 0 \cdot 4$ & $0 \cdot 0006$ \\
\hline MELD at LT or DO & $1 \cdot 1 \pm 0 \cdot 1$ & $<0 \cdot 0001$ \\
\hline WT (per month) & $0 \cdot 1 \pm 0 \cdot 03$ & $0 \cdot 001$ \\
\hline mRECIST progression disease & $-36 \cdot 8 \pm 0 \cdot 9$ & $<0 \cdot 0001$ \\
\hline Last radiological HCC assessment & $10 \cdot 9 \pm 0 \cdot 4$ & $<0 \cdot 0001$ \\
Major lesion diameter (cm) & $6 \cdot 5 \pm 0 \cdot 3$ & $<0 \cdot 0001$ \\
\hline Number of lesions & $-3 \cdot 4 \pm 0 \cdot 2$ & $<0 \cdot 0001$ \\
\hline Last available logAFP & \multicolumn{2}{|}{} \\
\hline
\end{tabular}

The constant term in the final model represents the estimated ITT survival benefit of LT in the mean patient. The covariates effects for the estimated ITT benefit are assumed to be additional to the constant term.

Abbreviations: SE, standard error; WL, waiting list; MELD, model for end-stage liver disease; LT, liver transplantation; DO, drop-out; WT, waiting time; mRECIST, modified response evaluation criteria in solid tumors; HCC, hepatocellular cancer; AFP, alpha-fetoprotein. 
Lai $Q$ et al. INTENTION-TO-TREAT SURVIVAL...

Table 3. ITT transplant benefit estimations in months in different subgroups.

\begin{tabular}{|c|c|c|c|c|}
\hline Variables & $\begin{array}{l}\text { Benefit in months } \\
\text { (n of patients) }\end{array}$ & $\begin{array}{l}\text { Benefit in months } \\
\text { (n of patients) }\end{array}$ & \multirow{2}{*}{$\begin{array}{l}\text { D value between } \\
\text { Groups (95\% CI) }\end{array}$} & \multirow[t]{2}{*}{ Difference } \\
\hline & No & Yes & & \\
\hline $\mathrm{WT} \geq 120$ days & $25 \cdot 5(1140)$ & $24 \cdot 0(963)$ & $0 \cdot 06(0 \cdot 01-0 \cdot 13)$ & Very small \\
\hline Age at listing $\geq 60$ years & $25 \cdot 5(1372)$ & $23 \cdot 6(731)$ & $0 \cdot 07(0 \cdot 02-0 \cdot 16)$ & Very small \\
\hline Last $\mathrm{AFP} \geq 20 \mathrm{ng} / \mathrm{mL}$ & $27 \cdot 0(1439)$ & $20 \cdot 3(664)$ & $0 \cdot 26(0 \cdot 17-0 \cdot 36)$ & Small \\
\hline MC-IN at LT or DO & $34 \cdot 5(496)$ & $22 \cdot 8(1607)$ & $0 \cdot 47(0 \cdot 37-0 \cdot 57)$ & Moderate* \\
\hline WL inscription before 2001 & $27 \cdot 3(1802)$ & $10 \cdot 4(301)$ & $0 \cdot 69(0 \cdot 57-0 \cdot 81)$ & Large§ \\
\hline Last AFP $\geq 1000 \mathrm{ng} / \mathrm{mL}$ & $25 \cdot 4(2040)$ & $6 \cdot 8(63)$ & $0 \cdot 74(0 \cdot 49-0 \cdot 99)$ & Large* \\
\hline mRECIST progression disease & $29 \cdot 2(1612)$ & $10 \cdot 6(491)$ & $0 \cdot 78(0 \cdot 67-0 \cdot 88)$ & Large* \\
\hline MELD at LT or DO $\leq 13$ & $39 \cdot 1(708)$ & $19 \cdot 8(1395)$ & $0 \cdot 81(0 \cdot 73-0 \cdot 90)$ & Large* \\
\hline mRECIST complete response & $28 \cdot 7(1723)$ & $7 \cdot 2(380)$ & $0 \cdot 90(0 \cdot 79-1 \cdot 01)$ & Large* \\
\hline \multicolumn{5}{|c|}{ Benefit Groups (*) } \\
\hline Group & Benefit in months & n of patients (\%) & & \\
\hline No benefit & 0 & $405(19 \cdot 2)$ & \multicolumn{2}{|c|}{ 3-4 negative factors } \\
\hline Small benefit & 20 & $897(42 \cdot 7)$ & \multicolumn{2}{|c|}{2 negative factors } \\
\hline Moderate benefit & 40 & $693(33 \cdot 0)$ & \multicolumn{2}{|c|}{1 negative factor } \\
\hline Large benefit & 60 & $108(5 \cdot 1)$ & \multicolumn{2}{|c|}{ No negative factors } \\
\hline
\end{tabular}

Continuous variables in Table 4 were dichotomized using relevant cut-off values used in the literature $(5,6,11,12)$.

Results are reported as means; D-value (effect size) values $<0 \cdot 1$ indicate very small differences; between $0 \cdot 1$ and 0.3 and between 0.3 and 0.5 indicate small and moderate differences, respectively, and $>0.5$ indicate large differences.

(*) Four risk factors were considered for constructing the benefit groups: MELD $\leq 13$; MC-IN; mRECIST progression disease or complete response; AFP $\geq 1000 \mathrm{ng} / \mathrm{mL}$. Benefit values in the groups were rounded to the nearest whole number.

(§) WL inscription before or after 2001 was not considered in the final group stratification because the period of WL inscription showed a very poor effect on survival benefit estimates (supplementary Tables 3-4) and it was not considered useful for the evaluation of the benefit in patients enlisted now.

Abbreviations: CI, confidence interval; WL, waiting list; WT, waiting time; AFP, alpha-fetoprotein; MC, Milan Criteria; LT, liver transplantation; DO, drop-out; MELD, model for end stage liver disease; mRECIST, modified response evaluation criteria in solid tumors. 


\begin{tabular}{|c|c|c|c|c|}
\hline A. Benefit risk factors & B. Median benefit & C. Median benefit gain & Months & \\
\hline WT $<120$ days & $25 \cdot 5$ & & \multirow{2}{*}{1.5} & \multirow{4}{*}{ 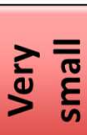 } \\
\hline WT $\geq 120$ days & $24 \cdot 0$ & & & \\
\hline Age at listing $<60$ years & $25 \cdot 5$ & & \multirow[t]{2}{*}{1.9} & \\
\hline Age at listing $\geq 60$ years & 23.6 & & & \\
\hline & & & \multirow{3}{*}{6.7} & \multirow{3}{*}{$\frac{\bar{\sigma}}{\frac{\sqrt{n}}{n}}$} \\
\hline Last AFP $<20 \mathrm{ng} / \mathrm{mL}$ & $27 \cdot 0$ & & & \\
\hline Last AFP $\geq 20 \mathrm{ng} / \mathrm{mL}$ & $20 \cdot 3$ & & & \\
\hline MC-OUT at LT or DO & 34.5 & & \multirow[b]{2}{*}{$11 \cdot 7$} & \multirow{5}{*}{$\begin{array}{l}\frac{0}{0} \\
\frac{0}{0} \\
\frac{0}{0} \\
\frac{0}{2}\end{array}$} \\
\hline $\begin{array}{l}\text { MC-OUT at LT or DO } \\
\text { MC-IN at LT or DO }\end{array}$ & 22.8 & & & \\
\hline WL inscription after 2001 & $27 \cdot 3$ & & \multirow{3}{*}{16.9} & \\
\hline WL inscription before 2001 & $10 \cdot 4$ & & & \\
\hline & & & & \\
\hline Last AFP $<1000 \mathrm{ng} / \mathrm{mL}$ & $25 \cdot 4$ & & \multirow[b]{2}{*}{$18 \cdot 6$} & \multirow{8}{*}{ 茄 } \\
\hline Last AFP $\geq 1000 \mathrm{ng} / \mathrm{mL}$ & 6.8 & & & \\
\hline mRECIST no progression disease & $29 \cdot 2$ & & \multirow{2}{*}{$18 \cdot 6$} & \\
\hline mRECIST progression disease & $10 \cdot 6$ & & & \\
\hline MELD at LT or DO $>13$ & $39 \cdot 1$ & & \multirow{2}{*}{$19 \cdot 3$} & \\
\hline MELD at LT or DO $\leq 13$ & 19.8 & & & \\
\hline mRECIST no complete response & 28.7 & & \multirow[b]{2}{*}{$21 \cdot 5$} & \\
\hline mRECIST complete response & 7.2 & & & \\
\hline & & 10 & & \\
\hline
\end{tabular}




\section{Supplementary Data 1}

The statistical design of this study included three main steps: a) the development of an ITT LT survival model; b) the development of a non-LT survival model and; c) the individual prediction of the ITT survival benefit of LT defined as the difference between the median ITT survival with LT (based on the first model) and median survival without LT (based on the second model) calculated for each enrolled patient.

\section{Step a) ITT LT survival model}

Length of follow-up and survival were expressed as medians (IQR). Overall survival was calculated from date of WL inclusion until death from any cause (before or after LT) or latest follow up. HCC patients dropping-out from the WL were followed until death or last follow-up. Survival curves were estimated using the Kaplan Meier method, whereas the statistical significance between survival curves was tested by the Log Rank test.

Several survival models (the semi-parametric Cox model, and parametric exponential, log-normal, Weibull, and log-logistic models) were tested; since the aim of this study was to develop a model able to give precise estimation of individual median survival after WL inclusion, it was decided to use an accelerated failure time parametric model. Among the different models available (gamma, log-logistic, lognormal), the log-logistic model was selected since it showed the lowest value of Akaike Information Criterion (AIC) at final multivariable model.

Finally, this model was applied to predict ITT median survival with LT of each enrolled patient.

Step b) Non-LT survival model

The prediction of non-LT survival using a WL population is controversial. The main statistical problem is that WL patients have relatively few failure events (death before LT) since the majority of them are censored by LT. Censoring related to LT, however, is an informative or dependent censoring since it depends on prioritization criteria used in each center. ${ }^{1,2}$ Moreover, median WT of 
HCC patients is relatively short, usually less than one year, thus prediction of long-term survival of these patients may be inaccurate. ${ }^{3}$

Some statistical techniques such as competing risk analysis, ${ }^{1,4}$ or inverse probability censoring weight have been used to overcome these problems. ${ }^{2}$ However, these methods seem still insufficient to resolve all the biases related to the complexity of WL dynamics and further corrections, sometime quite arbitrary, are necessary. ${ }^{4,5}$

Since it was aimed to predict median long-term survival of enrolled HCC patients $(n=2103)$ without LT, these statistical solutions were judged unsuitable for the present analysis.

The Model to Estimate the Survival In Ambulatory patients with HCC (MESIAH) has been recently developed with the specific aim to predict individual HCC patient survival. ${ }^{6}$ This model, proven to have a higher prognostic ability than that of available HCC prognostic systems, has been externally validated both in western and eastern countries. ${ }^{7,8}$

More importantly, the authors of this score provided a simple formula to translate the MESIAH score in individual survival predictions. Using patient characteristics at the last evaluation before LT or DO, we used the MESIAH score to simulate the median time to death that patients censored by LT would have had in the absence of LT. So, time to death of enrolled patients censored by LT $(\mathrm{n}=1857)$ was calculated as the sum of their true WL time (from listing to LT) and the simulated additional time they would have lived in the absence of LT.

This simulated time to death was therefore used to perform a second log-logistic parametric survival model to find significant predictors of non-LT survival.

Finally, we used this second model to predict non-LT median survival of each enrolled patient.

\section{Step c) ITT transplant benefit model}

The ITT LT and the non-LT survival log-logistic models generated two median survival predictions for each enrolled patient. The ITT survival benefit of LT was, therefore, calculated for each patient as the difference between ITT LT median and the non-LT median survival estimations. All 
estimations were capped at 120 months, since this time horizon represents the ideal balance between utility and urgency allocation principles. ${ }^{9}$ A multivariate least square regression was finally used to find significant predictors of ITT LT benefit among studied variables. ${ }^{10,11}$

2

4

5

6

7

8

9

10

11

12

13

14

15

16

17

18

19

20

21

22

23

24

25

26

27

28

29

30

31

32

33

34

35

36

37

38

39

40

41

42

43

44

45

46

47

48

49

50

51

52

53

54

55

56

57

58

59

60 
Lai $Q$ et al. INTENTION-TO-TREAT SURVIVAL...

\section{References}

1. Schaubel DE, Guidinger MK, Biggins SW, et al. Survival benefit-based deceased-donor liver allocation. Am J Transplant 2009;9:970-81.

1. Toso C, Dupuis-Lozeron E, Majno P, et al. A model for dropout assessment of candidates with or without hepatocellular carcinoma on a common liver transplant waiting list. Hepatology 2012;56:149-56.

3. Samoylova ML, Dodge JL, Yao FY, Roberts JP. Time to transplantation as a predictor of hepatocellular carcinoma recurrence after liver transplantation. Liver Transpl 2014;20:937-44.

4. Vitale A, Volk ML, De Feo TM, et al.; Liver Transplantation North Italy Transplant program (NITp) working group. A method for establishing allocation equity among patients with and without hepatocellular carcinoma on a common liver transplant waiting list. $J$ Hepatol 2014;60:290-7.

5. Berry K, Ioannou GN. Comparison of liver transplant-related survival benefit in patients with versus without hepatocellular carcinoma in the United States. Gastroenterology 2015;149:669-80.

6. Yang JD, Kim WR, Park KW, et al. Model to estimate survival in ambulatory patients with hepatocellular carcinoma. Hepatology 2012;56:614-21.

7. Farinati F, Vitale A, Spolverato G, et al.; ITA.LI.CA study group. Development and validation of a new prognostic system for patients with hepatocellular carcinoma. PLoS Med 2016;13:e1002006.

8. Kim BH, Park JW, Nam BH, Kwak HW, Kim WR. Validation of a model to estimate survival in ambulatory patients with hepatocellular carcinoma: a single-centre cohort study. Liver Int 2014;34:e317-23.

9. Lai Q, Lerut JP. Hepatocellular cancer: how to expand safely inclusion criteria for liver transplantation. Curr Opin Organ Transplant 2014;19:229-34.

10. Jacob M, Lewsey JD, Sharpin C, Gimson A, Rela M, von der Meulen JH. Systematic review and validation of prognostic models in liver transplantation. Liver Transpl 2005;11:814-25. 
11. Kalil AC, Mattei J, Florescu DF, Sun J, Kalil RS. Recommendations for the assessment and reporting of multivariable logistic regression in transplantation literature. Am J Transplant 2010; 10: $1695-1703$. 


\section{Supplementary Table 1}

Multivariate log-logistic parametric survival analysis evaluating significant predictors of ITT LT survival.

\begin{tabular}{|c|c|c|c|c|c|c|}
\hline \multirow{3}{*}{$\begin{array}{l}\text { Variables } \\
\text { WL inscription before } 2001\end{array}$} & \multirow{2}{*}{\multicolumn{2}{|c|}{$\begin{array}{c}\text { Univariate analysis } \\
\text { Coefficient } \pm \text { SE } \\
\text { p value }\end{array}$}} & \multirow{2}{*}{\multicolumn{2}{|c|}{$\begin{array}{c}\begin{array}{c}\text { First multivariable } \\
\text { model }(*)\end{array} \\
\text { Coefficient } \pm S E, \\
\text { p value }\end{array}$}} & \multirow{2}{*}{\multicolumn{2}{|c|}{$\begin{array}{c}\begin{array}{c}\text { Final multivariable } \\
\text { model }(* *)\end{array} \\
\text { Coefficient } \pm S E, \\
\text { p value }\end{array}$}} \\
\hline & & & & & & \\
\hline & $-0 \cdot 45 \pm 0 \cdot 14$ & $0 \cdot 002$ & $-0 \cdot 59 \pm 0 \cdot 15$ & $<0 \cdot 0001$ & $-0 \cdot 61 \pm 0 \cdot 14$ & $<0 \cdot 0001$ \\
\hline Male gender & $0 \cdot 14 \pm 0 \cdot 14$ & $0 \cdot 35$ & - & - & - & - \\
\hline Age at listing (per year) / 10 & $-0 \cdot 26 \pm 0 \cdot 06$ & $<0 \cdot 0001$ & $-0 \cdot 25 \pm 0 \cdot 06$ & $<0 \cdot 0001$ & $-0 \cdot 25 \pm 0 \cdot 06$ & $<0 \cdot 0001$ \\
\hline HCV positivity & $-0 \cdot 17 \pm 0 \cdot 11$ & $0 \cdot 12$ & - & - & - & - \\
\hline HBV positivity & $0 \cdot 07 \pm 0 \cdot 14$ & $0 \cdot 60$ & - & - & - & - \\
\hline Alcohol abuse history & $0 \cdot 10 \pm 0 \cdot 12$ & $0 \cdot 39$ & - & - & - & - \\
\hline MELD at LT or DO & $-0 \cdot 07 \pm 0 \cdot 01$ & $<0 \cdot 0001$ & $-0 \cdot 17 \pm 0 \cdot 09$ & $0 \cdot 07$ & $-0 \cdot 07 \pm 0 \cdot 01$ & $<0 \cdot 0001$ \\
\hline Albumin at LT or DO & $0 \cdot 75 \pm 0 \cdot 14$ & $<0 \cdot 0001$ & $-1 \cdot 17 \pm 1 \cdot 10$ & $0 \cdot 28$ & - & - \\
\hline WT (per month) & $0 \cdot 02 \pm 0 \cdot 01$ & $0 \cdot 0001$ & $0 \cdot 02 \pm 0 \cdot 01$ & $<0 \cdot 0001$ & $0 \cdot 02 \pm 0 \cdot 01$ & $<0 \cdot 0001$ \\
\hline $\begin{array}{l}\text { HCC at WL inscription } \\
\text { Major lesion diameter }(\mathrm{cm}) \\
\text { Number of lesions }\end{array}$ & $\begin{array}{c}-0 \cdot 09 \pm 0 \cdot 04 \\
0 \cdot 05 \pm 0 \cdot 03\end{array}$ & $\begin{array}{l}0.01 \\
0.08\end{array}$ & - & $\begin{array}{l}- \\
-\end{array}$ & $\begin{array}{l}- \\
-\end{array}$ & - \\
\hline No LRT & $-0 \cdot 08 \pm 0 \cdot 14$ & $0 \cdot 59$ & - & - & - & - \\
\hline Total number of LRT & $-0 \cdot 01 \pm 0 \cdot 02$ & 0.92 & - & - & - & - \\
\hline mRECIST complete response & $0 \cdot 35 \pm 0 \cdot 15$ & $0 \cdot 02$ & $-0 \cdot 06 \pm 0 \cdot 18$ & $0 \cdot 76$ & - & - \\
\hline mRECIST progression disease & $-1 \cdot 07 \pm 0 \cdot 12$ & $<0 \cdot 0001$ & $-1 \cdot 13 \pm 0 \cdot 13$ & $<0 \cdot 0001$ & $-1 \cdot 14 \pm 0 \cdot 13$ & $<0 \cdot 0001$ \\
\hline $\begin{array}{l}\text { Last radiological HCC assessment } \\
\text { Major lesion diameter }(\mathrm{cm}) \\
\text { Number of lesions }\end{array}$ & $\begin{array}{l}-0 \cdot 27 \pm 0 \cdot 05 \\
-0 \cdot 09 \pm 0 \cdot 04\end{array}$ & $\begin{array}{c}<\cdot 0001 \\
0 \cdot 02\end{array}$ & $\begin{array}{c}-0 \cdot 06 \pm 0 \cdot 07 \\
0 \cdot 10 \pm 0 \cdot 05\end{array}$ & $\begin{array}{l}0.38 \\
0.05\end{array}$ & $\stackrel{-}{0.08 \pm 0.04}$ & - \\
\hline $\begin{array}{l}\text { AFP } \\
\text { LogAFP at listing } \\
\text { Last available logAFP } \\
\text { Slope } \geq 15 \mathrm{ng} / \mathrm{mL} / \mathrm{month}\end{array}$ & $\begin{array}{l}-0 \cdot 12 \pm 0 \cdot 03 \\
-0 \cdot 22 \pm 0 \cdot 03 \\
-0 \cdot 62 \pm 0 \cdot 08\end{array}$ & $\begin{array}{l}0 \cdot 0004 \\
<0 \cdot 0001 \\
<0 \cdot 0001\end{array}$ & $\begin{array}{c}- \\
-0 \cdot 17 \pm 0 \cdot 03 \\
-\end{array}$ & $\begin{array}{c}- \\
<0 \cdot 0001 \\
-\end{array}$ & $\begin{array}{c}- \\
-0 \cdot 18 \pm 0 \cdot 03 \\
-\end{array}$ & $\begin{array}{c}- \\
<0 \cdot 0001 \\
-\end{array}$ \\
\hline
\end{tabular}

The negative sign indicates a negative impact on survival.

(*) In the first multivariable model all variables with $\mathrm{p}<0 \cdot 1$ at univariate model were included. The model showing the lowest AIC value was finally chosen.

(**) In the final model only variables showing a significant impact on survival at the first multivariable model were maintained. The model showing the lowest AIC value was chosen.

Abbreviations: SE, standard error; WL, waiting list; HCV, hepatitis C virus; HBV, hepatitis B virus; MELD, model for endstage liver disease; LT, liver transplantation; DO, drop-out; WT, waiting time; HCC, hepatocellular cancer; LRT, locoregional therapies; mRECIST, modified response evaluation criteria in solid tumors; AFP, alpha-fetoprotein. 


\section{Supplementary Table 2}

Multivariate Log-logistic parametric survival analysis evaluating significant predictors of non-LTsurvival.

\begin{tabular}{|c|c|c|c|c|c|c|}
\hline \multirow{3}{*}{$\begin{array}{l}\text { Variables } \\
\text { WL inscription before } 2001\end{array}$} & \multirow{2}{*}{\multicolumn{2}{|c|}{$\begin{array}{c}\text { Univariate analysis } \\
\text { Coefficient } \pm S E \\
\text { p value }\end{array}$}} & \multirow{2}{*}{\multicolumn{2}{|c|}{$\begin{array}{c}\text { First multivariable } \\
\text { model }(*)\end{array}$}} & \multirow{2}{*}{\multicolumn{2}{|c|}{$\begin{array}{c}\begin{array}{c}\text { Final multivariable } \\
\text { model }(* *)\end{array} \\
\text { Coefficient } \pm \text { SE, } \\
\text { p value }\end{array}$}} \\
\hline & & & & & & \\
\hline & $-0 \cdot 01 \pm 0 \cdot 05$ & $0 \cdot 89$ & $-0 \cdot 03 \pm 0 \cdot 02$ & $0 \cdot 25$ & $0 \cdot 05 \pm 0 \cdot 02$ & $0 \cdot 01$ \\
\hline Male gender & $0 \cdot 04 \pm 0 \cdot 14$ & $0 \cdot 35$ & - & - & - & - \\
\hline Age at listing (per year) / 10 & $-0 \cdot 13 \pm 0 \cdot 02$ & $<0 \cdot 0001$ & $-0 \cdot 17 \pm 0 \cdot 01$ & $<0 \cdot 0001$ & $-0 \cdot 17 \pm 0 \cdot 01$ & $<0 \cdot 0001$ \\
\hline HCV positivity & $-0 \cdot 01 \pm 0 \cdot 04$ & $1 \cdot 00$ & - & - & - & - \\
\hline HBV positivity & $0 \cdot 02 \pm 0 \cdot 04$ & 0.59 & - & - & - & - \\
\hline Alcol abuse history & $0 \cdot 02 \pm 0 \cdot 01$ & $0 \cdot 59$ & - & - & - & - \\
\hline MELD at LT or DO & $-0 \cdot 12 \pm 0 \cdot 01$ & $<0 \cdot 0001$ & $-0 \cdot 11 \pm 0 \cdot 01$ & $<0 \cdot 0001$ & $-0 \cdot 11 \pm 0 \cdot 01$ & $<0 \cdot 0001$ \\
\hline Albumin at LT or DO & $1 \cdot 36 \pm 0 \cdot 05$ & $<0 \cdot 0001$ & $0 \cdot 05 \pm 0 \cdot 24$ & $0 \cdot 83$ & - & - \\
\hline WT (per month) & $0 \cdot 01 \pm 0 \cdot 01$ & $<0 \cdot 0001$ & $0 \cdot 01 \pm 0 \cdot 01$ & $<0 \cdot 0001$ & $0 \cdot 01 \pm 0 \cdot 01$ & $<0 \cdot 0001$ \\
\hline $\begin{array}{l}\text { HCC at WL inscription } \\
\text { Major lesion diameter }(\mathrm{cm}) \\
\text { Number of lesions }\end{array}$ & $\begin{array}{l}-0 \cdot 07 \pm 0 \cdot 01 \\
-0 \cdot 13 \pm 0 \cdot 01\end{array}$ & $\begin{array}{l}<0 \cdot 0001 \\
<0 \cdot 0001\end{array}$ & $\begin{array}{l}- \\
-\end{array}$ & $\begin{array}{l}- \\
-\end{array}$ & $\begin{array}{l}- \\
-\end{array}$ & $\begin{array}{l}- \\
-\end{array}$ \\
\hline No LRT & $-0 \cdot 24 \pm 0 \cdot 05$ & $<0 \cdot 0001$ & $-0 \cdot 05 \pm 0 \cdot 02$ & $0 \cdot 02$ & - & - \\
\hline Total number of LRT & $0 \cdot 01 \pm 0 \cdot 01$ & 0.63 & - & - & - & - \\
\hline mRECIST complete response & $0 \cdot 55 \pm 0 \cdot 04$ & $<0 \cdot 0001$ & $-0 \cdot 16 \pm 0 \cdot 03$ & $<0 \cdot 0001$ & - & - \\
\hline mRECIST progression disease & $-0 \cdot 67 \pm 0 \cdot 04$ & $<0 \cdot 0001$ & $-0 \cdot 19 \pm 0 \cdot 03$ & $<0 \cdot 0001$ & $-0 \cdot 32 \pm 0 \cdot 02$ & $<0 \cdot 0001$ \\
\hline $\begin{array}{l}\text { Last radiological HCC assessment } \\
\text { Major lesion diameter }(\mathrm{cm}) \\
\text { Number of lesions } \\
\end{array}$ & $\begin{array}{l}-0 \cdot 35 \pm 0 \cdot 01 \\
-0 \cdot 22 \pm 0 \cdot 01 \\
\end{array}$ & $\begin{array}{l}<0 \cdot 0001 \\
<0 \cdot 0001\end{array}$ & $\begin{array}{l}-0 \cdot 22 \pm 0 \cdot 01 \\
-0 \cdot 10 \pm 0 \cdot 01 \\
\end{array}$ & $\begin{array}{l}<0 \cdot 0001 \\
<0 \cdot 0001 \\
\end{array}$ & $\begin{array}{l}-0 \cdot 20 \pm 0 \cdot 01 \\
-0 \cdot 06 \pm 0 \cdot 01 \\
\end{array}$ & $\begin{array}{l}<0 \cdot 0001 \\
<0 \cdot 0001\end{array}$ \\
\hline $\begin{array}{l}\text { AFP } \\
\text { LogAFP at listing } \\
\text { Last available logAFP } \\
\text { Slope } \geq 15 \mathrm{ng} / \mathrm{mL} / \mathrm{month} \\
\end{array}$ & $\begin{array}{l}-0 \cdot 06 \pm 0 \cdot 01 \\
-0 \cdot 13 \pm 0 \cdot 01 \\
-0 \cdot 35 \pm 0 \cdot 03 \\
\end{array}$ & $\begin{array}{l}<0 \cdot 0001 \\
<0 \cdot 0001 \\
<0 \cdot 0001\end{array}$ & $\begin{array}{c}- \\
-0 \cdot 07 \pm 0 \cdot 01 \\
- \\
\end{array}$ & $\begin{array}{c}- \\
<0 \cdot 0001 \\
-\end{array}$ & $\begin{array}{c}- \\
-0 \cdot 07 \pm 0 \cdot 01 \\
- \\
\end{array}$ & $\begin{array}{c}- \\
<0 \cdot 0001 \\
- \\
\end{array}$ \\
\hline $\begin{array}{l}\text { The negative sign indicates a nega } \\
\left({ }^{*}\right) \text { In the first multivariable model } \\
\text { AIC value was finally chosen. WL } \\
(* *) \text { In the final model only val } \\
\text { maintained. The model showing th } \\
\text { Abbreviations: SE, standard error; } \\
\text { stage liver disease; LT, liver trar } \\
\text { regional therapies; mRECIST, mo }\end{array}$ & $\begin{array}{l}\text { mpact on survi } \\
\text { yariables with } 1 \\
\text { ription was ma } \\
\text { es showing a } \\
\text { vest AIC value } \\
\text {, waiting list; I } \\
\text { ntation; DO, } \\
\text { response eval }\end{array}$ & $\begin{array}{l}1 . \\
0 \cdot 1 \text { at unive } \\
\text { tained in th } \\
\text { snificant ir } \\
\text { as finally c } \\
\text { V, hepatiti } \\
\text { p-out; WT } \\
\text { tion criteri }\end{array}$ & $\begin{array}{l}\text { ate model } \mathrm{w} \\
\text { model for ho } \\
\text { act on surv } \\
\text { sen. } \\
\mathrm{C} \text { virus; HB } \\
\text { waiting time } \\
\mathrm{n} \text { solid tumo }\end{array}$ & $\begin{array}{l}\text { included. } \\
\text { geneity wi } \\
\text { at the fi } \\
\text { lepatitis B } \\
\text { ICC, hepa } \\
\text { AFP, alph }\end{array}$ & $\begin{array}{l}\text { model show } \\
\text { e ITT-LT sL } \\
\text { nultivariabl } \\
\text { s; MELD, r } \\
\text { llular cance } \\
\text { oprotein. }\end{array}$ & $\begin{array}{l}\text { he lowest } \\
\text { al model. } \\
\text { del were } \\
1 \text { for end- } \\
\text { RT, loco- }\end{array}$ \\
\hline
\end{tabular}




\section{Supplementary Table 3}

Multivariate log-logistic parametric survival analyses evaluating significant predictors of ITT LT and non-LT - survival in patients listed after 01/01/2001 $(n=1802)$.

\begin{tabular}{|c|c|c|c|c|}
\hline \multirow{3}{*}{$\begin{array}{l}\text { Variables } \\
\text { Age at listing (per year) / } 10\end{array}$} & \multirow{2}{*}{\multicolumn{2}{|c|}{$\begin{array}{c}\begin{array}{c}\text { ITT LT multivariable } \\
\text { model }(*)\end{array} \\
\begin{array}{c}\text { Coefficient } \pm \text { SE } \\
\text { p value }\end{array}\end{array}$}} & \multirow{2}{*}{\multicolumn{2}{|c|}{$\begin{array}{c}\text { Non-LT multivariable } \\
\text { model }(* *)\end{array}$}} \\
\hline & & & & \\
\hline & $-0 \cdot 21 \pm 0 \cdot 07$ & $<0 \cdot 0001$ & $-0 \cdot 17 \pm 0 \cdot 01$ & $<0 \cdot 0001$ \\
\hline MELD at LT or DO & $-0 \cdot 08 \pm 0 \cdot 01$ & $<0 \cdot 0001$ & $-0 \cdot 11 \pm 0 \cdot 01$ & $<0 \cdot 0001$ \\
\hline WT (per month) & $0 \cdot 02 \pm 0 \cdot 01$ & $0 \cdot 0017$ & $0 \cdot 01 \pm 0 \cdot 01$ & $<0 \cdot 0001$ \\
\hline mRECIST progression disease & $-1 \cdot 26 \pm 0 \cdot 14$ & $<0 \cdot 0001$ & $-0 \cdot 47 \pm 0 \cdot 02$ & $<0 \cdot 0001$ \\
\hline $\begin{array}{l}\text { Last radiological HCC assessment } \\
\text { Major lesion diameter }(\mathrm{cm}) \\
\text { Number of lesions }\end{array}$ & $\begin{array}{c}- \\
0 \cdot 13 \pm 0 \cdot 04\end{array}$ & $0 \cdot 0034$ & $\begin{array}{l}-0 \cdot 19 \pm 0 \cdot 01 \\
-0 \cdot 04 \pm 0 \cdot 01\end{array}$ & $\begin{array}{l}<0 \cdot 0001 \\
<0 \cdot 0001\end{array}$ \\
\hline Last available $\log \mathrm{AFP}$ & $-0 \cdot 19 \pm 0 \cdot 03$ & $<0 \cdot 0001$ & $-0 \cdot 08 \pm 0 \cdot 01$ & $<0 \cdot 0001$ \\
\hline \multicolumn{5}{|c|}{$\begin{array}{l}\text { The negative sign indicates a negative impact on survival. } \\
\text { Abbreviations: SE, standard error; WL, waiting list; HCV, hepatitis C virus; HBV, hepatitis B } \\
\text { virus; MELD, model for end-stage liver disease; LT, liver transplantation; DO, drop-out; WT, } \\
\text { waiting time; HCC, hepatocellular cancer; LRT, loco-regional therapies; mRECIST, modified } \\
\text { response evaluation criteria in solid tumors; AFP, alpha-fetoprotein. }\end{array}$} \\
\hline
\end{tabular}




\section{Supplementary Table 4}

Multivariate least square regression evaluating significant predictors of ITT transplant benefit in patients listed after 01/01/2001 $(\mathrm{n}=1802)$.

\begin{tabular}{|l|c|c|}
\hline \multirow{2}{*}{ Variables } & \multicolumn{2}{|c|}{ Multivariable model } \\
\cline { 2 - 3 } & Coefficient \pm SE & p value \\
\hline Constant & $-26 \cdot 7 \pm 3 \cdot 0$ & $<0 \cdot 0001$ \\
\hline Age at listing (per year) / 10 & $3 \cdot 0 \pm 0 \cdot 4$ & $<0 \cdot 0001$ \\
\hline MELD at LT or DO & $1 \cdot 1 \pm 0 \cdot 1$ & $<0 \cdot 0001$ \\
\hline WT (per month) & $0 \cdot 1 \pm 0 \cdot 04$ & $0 \cdot 001$ \\
\hline mRECIST progression disease & $-37 \cdot 6 \pm 1 \cdot 0$ & $<0 \cdot 0001$ \\
\hline Last radiological HCC assessment & & $<0 \cdot 0001$ \\
Major lesion diameter (cm) & $11 \cdot 1 \pm 0 \cdot 5$ & $<0 \cdot 0001$ \\
\hline Number of lesions & $6 \cdot 6 \pm 0 \cdot 4$ & $<0 \cdot 0001$ \\
\hline Last available logAFP & $-2 \cdot 8 \pm 0 \cdot 2$ & \\
\hline
\end{tabular}

The constant term in the final model represents the estimated ITT survival benefit of LT in the mean patient. The covariates effects for the estimated ITT benefit are assumed to be additional to the constant term.

Abbreviations: SE, standard error; WL, waiting list; MELD, model for end-stage liver disease; LT, liver transplantation; DO, drop-out; WT, waiting time; mRECIST, modified response evaluation criteria in solid tumors; HCC, hepatocellular cancer; AFP, alpha-fetoprotein. 

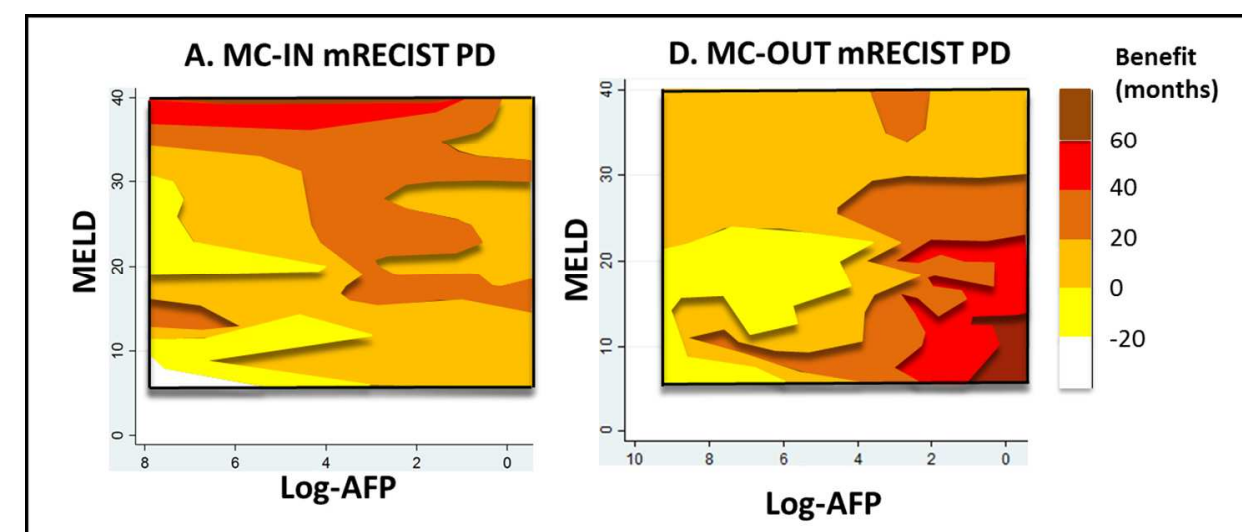

B. MC-IN mRECIST no PD nor CR

E. MC-OUT mRECIST no PD
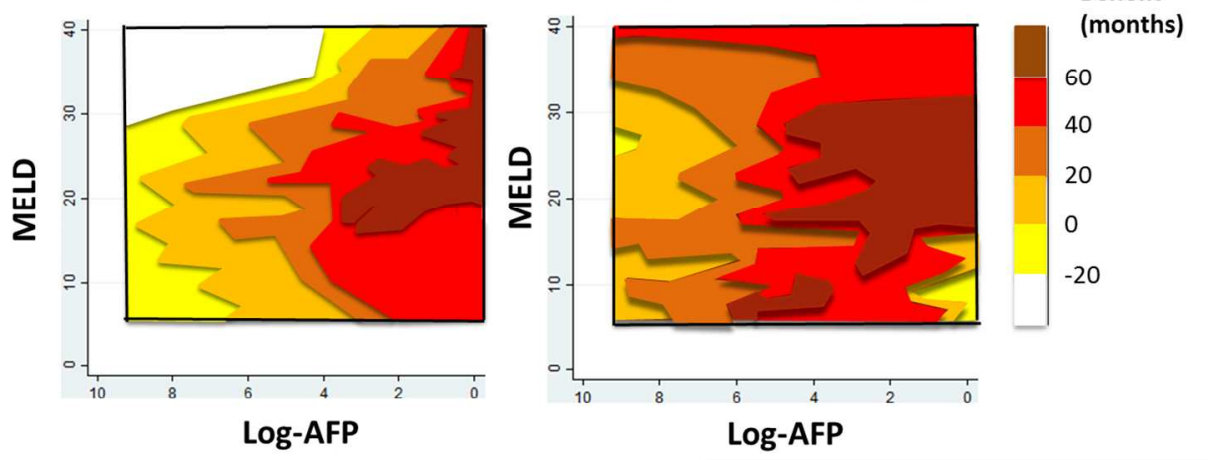

C. MC-IN MRECIST CR

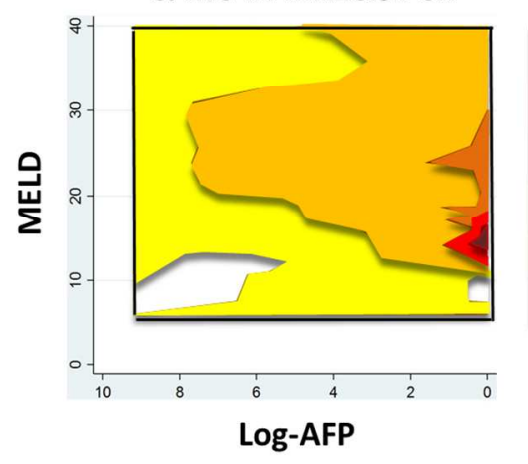

Contour plots of the ITT benefit according to 4 variables (MC status, radiological response, MELD and AFP).

A. MC-IN status, PD.

B. MC-IN status, no PD nor CR.

C. MC-IN status, CR.

D. MC-OUT status, PD.

E. MC-OUT status, no PD. No cases of CR were reported among MC-OUT patients. 